\title{
Dinâmica Intergeracional de Educação e Corresidência entre Pais e Filhos Adultos no Brasil
}

\section{Intergenerational Mobility of Education and Coresidence Decision between Adult Children and Parents in Brazil}

Hilton Martins de Brito Ramalho* José Luis da Silva Netto Júnior**

Resumo: Este artigo busca analisar a mobilidade intergeracional de educação no Brasil considerando sua possível inter-relação com a decisão de corresidência entre filhos adultos e pais no mesmo domicílio. Foram usados os dados da Pesquisa Nacional por Amostra de Domicílio (PNAD) de 1996 incorporando sua amostragem complexa e um modelo empírico de decisão conjunta de corresidência e acumulação de capital humano com autosseleção de filhos de acordo com sua posição familiar. Os resultados sugerem que os coeficientes de persistência educacional não podem ser generalizados devido ao viés de seleção amostral. Ademais, foram encontradas evidências de uma maior mobilidade para o grupo de filhos corresidentes com os pais na vida adulta em relação a filhos que são chefes ou cônjuges nos domicílios pesquisados.

Palavras-chave: Mobilidade intergeracional. Capital humano. Corresidência.

\begin{abstract}
This article aims to analyze the intergenerational mobility of education in Brazil considering the effects of coresidence decision between adult children and parents. The empirical analyses are based on complex survey data of Pesquisa Nacional por Amostra de Domicílio (PNAD) of 1996 and a model of joint decision of coresidence and accumulation of human capital with self-selection of children according to their family position. The results suggest that the coefficients of educational persistence cannot be generalized due to sample selection bias. In addition, evidence of greater mobility was found for the group of coresident children with parents in adult life compared to children who are heads or spouses in the households surveyed.
\end{abstract}

Keywords: Intergerational mobility. Human capital. Coresidence.

JEL Classification: J24; J62; C24.

\footnotetext{
* $\quad$ Doutor em Economia pelo Programa de Pós-Graduação em Economia (PIMES) da Universidade Federal de Pernambuco (UFPE). Professor do Departamento de Economia da Universidade Federal da Paraíba (UFPB). E-mail: hilton@ccsa.ufpb.br

** Doutor em Economia pelo Programa de Pós-Graduação em Economia (PPGE) da Universidade Federal do Rio Grande do Sul. Professor do Departamento de Economia da Universidade Federal da Paraíba (UFPB). E-mail: juniorluis@yahoo.com
} 


\section{1 lntrodução}

O processo de acumulação de capital humano tem um importante papel no tocante ao crescimento econômico e distribuição de renda (LUCAS, 1988; BECKER; MURPHY; TAMURA, 1990). Entre os fatores que afetam este processo de acumulação vale destacar a estrutura e as características componentes do ambiente familiar. Nesse contexto, a decisão de investimento em capital humano dos filhos, por exemplo, é em grande parte determinada por escolhas feitas pelos pais. Desse modo, é razoável sugerir que as decisões de natureza familiar têm um grande papel na trajetória educacional dos filhos (BECKER, 1993).

Em paralelo, é importante destacar que a localização espacial também pode influenciar nas decisões que envolvem alocação de recursos para investimento em capital humano. Deste modo, em áreas mais dinâmicas economicamente espera-se que exista um ambiente mais propício para o investimento em educação que em áreas menos desenvolvidas. Portanto, é razoável assumir a existência de uma interação entre os determinantes familiares (efeito local) e fatores associados à localização espacial (efeito externo) no tocante às decisões de investimento em capital humano (GALOR; ZEIRA, 1993; GALOR; TSIDDON, 1997).

No Brasil, a literatura empírica que trata da dinâmica intergeracional educacional e de renda explora, em sua maior parte, as informações da Pesquisa Nacional por Amostra de Domicílios (PNAD) de 1996 (BEHRMAN et al., 2001; FERREIRA; VELOSO, 2003; FERREIRA; VELOSO, 2006; MACHADO; GONZAGA, 2007; PERO; SZERMAN, 2008). O citado suplemento social apresenta informações dos pais dos entrevistados (pessoas de referência no domicílio - chefes ou cônjuges) que não necessariamente residem no mesmo domicílio ou residem sob os cuidados dos filhos. Destarte, grande parte dos resultados concernentes à dinâmica intergeracional educacional (BEHRMAN et al., 2001; FERREIRA; VELOSO, 2003) e de renda (FERREIRA; VELOSO, 2006; PERO; SZERMAN, 2008) não consideram o papel da corresidência entre os pares de pais e filhos até a fase adulta dos últimos, em queo pai assume a responsabilidade do domicílio.

A decisão de convivência com os pais durante a vida adulta pode ser resultado de um processo não aleatório e inerente ao planejamento do investimento em capital humano, de modo que os grupos de filhos corresidentes e não corresidentes sejam distintos em atributos socioeconômicos observados e características produtivas não observadas (motivação, perseverança, propensão ao risco, etc.). Sob tal premissa, estimativas de indicadores de persistência intergeracional de educação, considerando apenas um dos grupos citados, podem incorrer em viés de seleção amostral (viés de omissão de variáveis) (HECKMAN, 1979; HECKMAN,1990).

Neste sentido, o conhecimento de estimativas precisas de coeficientes de persistência intergeracional de educação é fundamental para o norteamento de 
políticas educacionais de longo prazo devido aos seus rebatimentos sobre a produtividade da economia e nível de renda. Adicionalmente, é de extrema relevância o conhecimento dos determinantes associados à decisão de acumulação de capital humano de adultos jovens, dadas suas possíveis repercussões na oferta de trabalho. Tais aspectos são relacionados a algumas questões de interesse, a saber: (a) Qual é a intensidade média de mobilidade intergeracional de educação no Brasil? (b) Em que medida a decisão de corresidência de filhos adultos com os pais influencia a transmissão intergeracional de educação? Portanto, o presente estudo aborda dois pontos no contexto analítico associado à dinâmica educacional intergeracional: i) propõe medidas mais robustas de mobilidade educacional e ii) faz considerações a respeito da relação entre a decisão de acumulação de capital humano e corresidência.

Dada esta introdução, o objetivo geral deste estudo é avaliar o grau de transmissão intergeracional de educação no Brasil. De forma específica, busca-se testar a hipótese de que a não contabilização de filhos (adultos) corresidentes na análise de transmissão intergeracional de educação pode gerar vieses na estimativa de indicadores de persistência/mobilidade. Para tanto, usando dados da PNAD de 1996 e um modelo de determinação conjunta de corresidência e acumulação de capital humano (endogenous switching regression) faz-se uma comparação e uma revisão dos resultados do estudo de Ferreira e Veloso (2003) à luz de possíveis efeitos de transmissão de educação gerados pela corresidência de pais e filhos na vida adulta.

Além desta introdução este artigo está divido em mais cinco seções. Na segunda parte é apresentada uma breve revisão da literatura empírica que trata do tema de estudo. As considerações a respeito do método e base de dados são descritas na terceira seção. A quarta parte apresenta resultados do estudo e a quinta as considerações finais.

\section{Revisão da Literatura}

Os estudos empíricos que tratam da mobilidade intergeracional baseiam-se na ideia de que existe uma relação entre estoque de capital de capital humano dos pais e filhos. O efeito dos pais sobre a trajetória educacional dos filhos (efeito local) é captado pelas mais variadas medidas de persistência que mensuram o quanto os filhos tendem a ser "iguais" aos seus pais. Neste sentido, uma alta persistência sugere uma baixa mobilidade intergeracional enquanto que uma baixa persistência se baseia em uma menor chance de os filhos terem trajetória semelhante dos pais. ${ }^{1}$

$1 \quad$ Uma maior mobilidade é sempre entendida como uma melhora dos indicadores, mas por definição, uma maior mobilidade pode estar associada também a uma piora (FIELDS; OK, 1996). Contudo, é assumido neste artigo que um aumento da mobilidade intergeracional educacional está associada a um aumento da média de anos de estudo e à redução da desigualdade educacional. 
A literatura empírica que investiga questões relativas à mobilidade intergeracional educacional data, em sua grande parte, do final da década de 1990 e início dos anos 2000. No tocante aos determinantes familiares associados à escolaridade merecem destaque os estudos de Barros e Lam (1993) e Barros et al. (2001). No primeiro é feita uma análise da influência dos pais quanto à trajetória dos filhos com idade de 14 anos, residentes em áreas urbanas, nas regiões Sudeste e Nordeste usando os dados da PNAD de 1982. O último trata da mesma temática só que, desta vez, ampliando a faixa etária para 11 a 25 anos, tendo como base a PNAD de 1996. Contudo, os dois estudos ressaltam a importância das características familiares para o desempenho educacional dos filhos e assimetrias quanto a este efeito do ponto de vista espacial.

É importante ressaltar que a persistência dos efeitos dos pais engloba diversas outras variáveis (lar monoparental ou biparental, gênero, cor da pele, idade, etc.) que compõem o chamado efeito familiar. Este conjunto de fatores, por sua vez, interage com aspectos associados ao ambiente externo (características locacionais). Assim, é de se esperar que em áreas onde exista uma dinâmica econômica mais intensa haja infraestrutura e incentivos maiores para o investimento em acumulação de capital humano (GALOR; ZEIRA, 1993; GALOR; TSIDDON, 1997).

O estudo de Behrman et al. (2001) foi um dos primeiros a abordar os impactos das reformas econômicas ocorridas na América Latina sobre os indicadores de pobreza e desigualdade de renda tendo como um dos objetivos estimar o grau de mobilidade intergeracional educacional. Em linhas gerais, os autores em destaque, tendo como base os dados do suplemento social da PNAD de 1996, encontraram evidências que sugerem uma elevada persistência educacional no Brasil, ou seja, baixa mobilidade intergeracional educacional mesmo se comparado aos países latino-americanos.

No artigo de Ferreira e Veloso (2003), tendo como base também o suplemento social do censo de1996, observou-se uma alta persistência intergeracional educacional no Brasil se comparado aos demais países latino-americanos. Em paralelo, também foi constatada uma assimetria na relação escolaridade do pai e filho de acordo o nível de escolaridade, região geográfica e características familiares. Vale salientar que tanto o estudo em foco quanto o de Behrman et al. (2001) não consideraram os filhos corresidentes, ou seja, aqueles que ainda moram com os pais na idade adulta.

Considerando as pesquisas que assumem apenas os pais e filhos corresidentes merecem destaque os artigos de Figueirêdo, Netto Júnior e Pôrto Júnior (2007) e Netto Júnior, Pôrto Júnior e Figueirêdo (2007). O primeiro trabalho utiliza informações das PNAD de 1987 a 2005. Sua principal conclusão é que ao longo deste período houve um aumento da mobilidade intergeracional educacional associada a uma redução da persistência do pai analfabeto. O último estudo, tendo como 
base de dados os microdados do Censo Demográfico do IBGE de 2000, ressalta a grande heterogeneidade da dinâmica educacional inter-regional e como ela se diferencia considerando indivíduos migrantes e não migrantes.

$\mathrm{Na}$ literatura empírica internacional voltada para mobilidade intergeracional educacional e de rendimentos, grande parte dos estudos documentados tem como base de dados informações longitudinais de famílias (ATKINSON, 1981; BORJAS, 1992; MULLIGAN, 1997). Em geral, a preocupação básica destas pesquisas reside na determinação da persistência intergeracional. As principais evidências sugerem que existe uma relação forte entre o nível educacional dos pais e de seus filhos.

Quanto aos determinantes da mobilidade educacional merecem destaque os estudos de Ermisch e Francesconi (2001) e Nicoletti e Ermisch (2008) para Grã-Bretanha. Essas pesquisas enfatizam a importância da escolaridade dos pais e da dotação de riqueza para a mobilidade intergeracional educacional. De acordo com os resultados de Ermisch e Francesconi (2001), há baixa mobilidade intergeracional em lares monoparentais. No estudo de Nicoletti e Ermisch (2008), os resultados sugerem que a mobilidade intergeracional não tem mudanças significativas para indivíduos nascidos em 1950 e 1972.

No tocante às decisões de acumulação de capital humano, corresidência e nível educacional e de renda, a literatura empírica internacional apresenta evidências consonantes. Giannelli e Monfardini (2003), por exemplo, tendo como base os dados de pesquisa familiar do Banco da Itália, concluem que o tempo de corresidência, que é também afetado pelos custos de moradia, e o nível de renda familiar estão diretamente associados com a decisão de acumulação de capital humano. Na mesma linha investigativa, Cobb-Clark e Gorgens (2014), cuja fonte de dados é o Youth in Focus da Austrália, sugerem que existe uma relação positiva entre apoio dos pais e investimento em educação, considerando corresidentes, e indica uma relação direta entre nível de renda e média de idade de filhos corresidentes. Já o estudo de Sá et al. (2011) mostra que quanto maior for o nível de renda e de educação familiar mais provável que os estudantes pesquisados permaneçam com os pais.

\section{Estratégia Empírica}

Esta seção apresenta a estratégia empírica deste trabalho. Primeiro, faz-se uma breve descrição das matrizes de transição de Markov, abordagem não paramétrica para a análise de mobilidade intergeracional de educação. Segundo, apresenta-se o modelo econométrico empregado para investigar os determinantes da decisão de convivência com os pais e acumulação de capital humano dos filhos. 


\subsection{Matrizes de Transição}

Segundo Bickenbach e Bode (2001), uma cadeia de Markov é um processo estocástico no qual a probabilidade $p_{i j}$ de uma variável aleatória $X$ estar em um estado $j$ em qualquer ponto do tempo $t+1$ depende apenas do estado $i$ em que ela estava em $t$, não importando os estados em períodos anteriores. Formalmente:

$$
P\left[X(t+1)=j \mid X(0)=i_{0}, \ldots, X(t-1)=i_{t-1}\right]=P[X(t+1)=j \mid X(t)=i]=p_{i j}
$$

Quando a variável aleatória X(t) está definida em um espaço de estado discreto, então, se o processo for constante ao longo do tempo, a cadeia de Markov é completamente determinada pela matriz de transição linha-estocástica:

$$
\Pi=\left[\begin{array}{ccc}
p_{11} & \cdots & p_{1 N} \\
\vdots & \ddots & \vdots \\
p_{N 1} & \cdots & p_{N N}
\end{array}\right], p_{i j} \geq 0, \sum_{j=1}^{N} p_{i j}=1
$$

O processo de transição de Markov, resumido em (1) e (2), pode ser usado para descrever o fenômeno de mobilidade intergeracional. Vale observar que as entradas da matriz (2) são não negativas e suas colunas e linhas têm soma igual a 1 (um), pois os elementos são probabilidades condicionais e o processo tem que realizar uma transição para algum estado (SIMON; BLUME, 1994).

Bickenbach e Bode (2001) ressaltam que a confiabilidade das probabilidades de transição estimadas depende de dois aspectos. Primeiro, o processo de geração de dados deve ser markoviano, ou seja, atender ao pressuposto de invariância no tempo. Caso contrário, os estimadores $p_{i j}$ não podem ser interpretados como probabilidades de transição e não devem ser usados para derivar uma distribuição estacionária. O segundo diz que as estimativas devem ser feitas com um número suficientemente grande de observações, pois o contrário pode não permitir inferências confiáveis devido ao alto grau de incerteza.

Atendidos esses dois aspectos, cada elemento $p_{i j}$ da matriz de transição (2) fornece a probabilidade que um determinado filho pertença a um estrato educacional $i$, dado que seu pai pertencia ao estrato educacional $j$. A diagonal principal das matrizes de mensura a probabilidade de os filhos permanecerem no mesmo estrato educacional dos pais, ou seja, métricas de persistência intergeracional de educação. 


\subsection{Modelo Econométrico}

Esta subseção está dividida em três partes. Na primeira, aborda-se a especificação do modelo empírico de determinação conjunta de corresidência com os pais e acumulação de capital humano. Na segunda, faz-se uma discussão sobre a estratégia de estimação do modelo. Por fim, na terceira, apresenta-se o teste de identificação de efeito causal a partir da variável instrumental empregada.

\subsubsection{Especificação}

Vários estudos documentados na literatura especializada adotaram um modelo de regressão linear simples para captar, a partir de uma medida sintética, o efeito da transmissão educacional dos pais para os filhos (BORJAS, 1992; COUCH; DUNN, 1997; BEHRMAN et al., 2001; FERREIRA; VELOSO, 2003). Formalmente, a equação de transmissão educacional pode ser descrita a seguir:

$$
S_{i}^{f}=\alpha+\beta S_{i}^{p}+\theta^{\prime} X_{i}+\varepsilon_{i}
$$

Onde $S_{i}^{f}$ é o nível de instrução do filho adulto; $S_{i}^{p}$ o nível de escolaridade do pai; $X_{i}$ é um vetor de características socioeconômicas e regionais; $\alpha$ e $\beta$ coeficientes; $\theta$ é um vetor de parâmetros e $\varepsilon_{i}$ um termo randômico normalmente distribuído e com variância constante.

Nesse modelo, o coeficiente $\beta$ tem um papel central, uma vez que fornece uma medida do grau de persistência intergeracional de educação. Destarte, quanto maior o valor do referido coeficiente, menor deve ser o grau de mobilidade intergeracional. Conforme destacado por Ferreira e Veloso (2003), a medida 1 - $\beta$ fornece o grau de mobilidade intergeracional de educação, ou seja, quanto menor seu valor, maior será a mobilidade.

A maioria dos estudos internacionais e nacionais sobre a temática em destaque ignorou a possibilidade de a amostra ser não aleatória, justamente por não considerar a decisão de filhos adultos em permanecer no domicílio sob a tutela dos pais como parte inerente ao plano de acumulação de capital humano (BEHRMAN et al., 2001; FERREIRA; VELOSO, 2003; MACHADO; GONZAGA, 2007; PERO; SZERMAN, 2008). Nesse contexto, é possível que diferenças em atributos observados (grau de instrução) e não observados (altruísmo, motivação, perseverança, propensão ao risco) afetem a decisão conjunta de corresidência com os pais na vida adulta e a estratégia de investimento em capital humano. Portanto, a estimativa convencional da equação (3) por Mínimos Quadrados Ordinários (MQO) pode produzir parâmetros tendenciosos (HECKMAN, 1979), de modo que a medida de 
persistência estimada $\beta$ pode não representar o verdadeiro parâmetro da população e mascarar comparações internacionais.

Diante desse problema, optou-se pela utilização de um modelo de seleção com mudança endógena de regime (Endogenous Switching Regression - Tobit tipo 5), método que permite averiguar se o indivíduo decide permanecer ou sair do domicílio chefiado pelo pai de acordo com as vantagens comparativas em termos de resultados potenciais decorrentes do investimento em educação (TOOMET; HENNINGSEN, 2008).

Considere-se que a decisão de conviver ou não com os pais durante a vida adulta depende do benefício esperado resultante do capital humano esperado em cada regime, conforme a equação a seguir:

$$
U_{i}^{*}=\delta\left(S_{i}^{f C *}-S_{i}^{f n c *}\right)+\mu^{\prime} Z_{i}+v_{i},\left\{\begin{array}{l}
D=1 \leftrightarrow U_{i}^{*} \geq 0 \\
D=0 \leftrightarrow U_{i}^{*}<0
\end{array}\right.
$$

Onde $U_{i}^{*}$ é uma variável latente não observada que mensura o benefício líquido do filho derivado da opção de corresidência com os pais quando adulto; $D$ é uma variável indicadora (binária) que assume o valor 1 caso se observe o regime de corresidência (grupo tratado) e 0 caso contrário (grupo de controle); $Z_{i}$ é um vetor

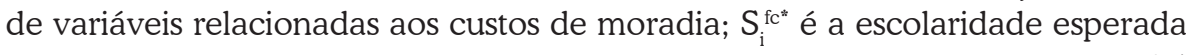
(potencial), caso o filho opte por residir com seus pais durante a vida adulta; $\mathrm{S}_{i}^{\text {fnc* }}$ é o grau de instrução potencial do filho no cenário (regime) de não convivência com seus pais quando adulto; $\delta$ é um parâmetro estrutural que capta o retorno de bem-estar oriundo da acumulação de capital humano sob o regime de corresidência (efeito médio da mudança de regime/tratamento); o vetor $\mu$ inclui parâmetros estruturais relacionados a custos de moradia $\mathrm{e}_{\mathrm{i}}$ um termo de erro probabilístico associado a fatores não observados e relacionados aos custos de moradia.

Cabe observar que as estimativas de $\delta$ e $\mu$ não podem ser obtidas diretamente em razão de um problema de autosseleção dos filhos em diferentes regimes. O nível de educação dos filhos é apenas observado de acordo com a condição domiciliar escolhida (regime), ainda que condicionado à escolaridade do pai e por atributos socioeconômicos: $S_{i}^{\text {fc }}=S_{i}^{\text {fcc }} \leftrightarrow U_{i}^{*} \geq 0$ e $S_{i}^{\text {fnc }}=S_{i}^{\text {fnct }} \leftrightarrow U_{i}^{*}<0$, onde $S_{i}^{\text {fc }}$ e $S_{i}^{\text {fnc }}$ são valores observados em cada regime. Ou seja, não é possível observar a escolaridade dos filhos em um regime contrafatual. Para contornar esse problema de censura, são consideradas duas equações detransmissão intergeracional de educação, respectivamente, para não corresidentes (ou filhos não dependentes) e filhos corresidentes (ou filhos dependentes): 


$$
\mathrm{S}_{\mathrm{i}}^{\mathrm{fnc}}=\alpha_{0}+\beta_{0} \mathrm{~S}_{0 \mathrm{i}}^{\mathrm{p}}+\theta_{0}{ }^{\prime} \mathrm{X}_{0 \mathrm{i}}+\varepsilon_{0 \mathrm{i}}
$$

e

$$
\mathrm{S}_{\mathrm{i}}^{\mathrm{fc}}=\alpha_{1}+\beta_{1} \mathrm{~S}_{\mathrm{Ii}}^{\mathrm{p}}+\theta^{\prime} \mathrm{X}_{\mathrm{Ii}}+\varepsilon_{\mathrm{li}}
$$

Onde $\mathrm{X}_{\mathrm{oi}}$ e $\mathrm{X}_{1 \mathrm{i}}$ são vetores de atributos pessoais e de localização; $\alpha_{0}$ e $\alpha_{1}$ coeficientes de intercepto, $\beta_{0}$ e $\beta_{1}$ coeficientes de persistência intergeracional por regime; $\theta_{0}$ e $\theta_{1}$ vetores de parâmetros e $\varepsilon_{0 \mathrm{i}}$ e $\varepsilon_{1 \mathrm{i}}$ são termos de erros randômicos normalmente distribuídos e com variância constante.

Substituindo (5) e (6) em (4), chega-se à forma reduzida do sistema de equações acima:

$$
\mathrm{U}_{\mathrm{i}}^{*}=\phi+\mathrm{W}_{\mathrm{i}} \pi+\epsilon_{\mathrm{i}}
$$

Onde $\left[\mathrm{S}_{0 \mathrm{i}}{ }^{\mathrm{p}}, \mathrm{S}_{1 \mathrm{i}}{ }^{\mathrm{p}}, \mathrm{X}_{0 \mathrm{i}}, \mathrm{X}_{\mathrm{li}}, \mathrm{Z}_{\mathrm{i}}\right] \subset \mathrm{W}_{\mathrm{i}}$ é uma matriz que inclui as covariadas das equações (4), (5) e (6); ф é uma constante de intercepto; $\pi$ é uma matriz de parâmetros e $\left[\mathrm{v}_{\mathrm{i}}, \varepsilon_{0 \mathrm{i}}, \varepsilon_{1 \mathrm{i}}\right] \subset \epsilon_{\mathrm{i}}$ uma variável aleatória correlacionada com os termos $\varepsilon_{0 \mathrm{i}}$ e $\varepsilon_{1 \mathrm{i}}$ a partir dos seguintes coeficientes de correlação linear $\rho_{\epsilon 0}$ e $\rho_{\epsilon 1}$, respectivamente. ${ }^{2}$

\subsubsection{Estimação}

Lee (1978) e Heckman (1979) desenvolveram uma técnica de correção para viés de seleção amostral baseada em propriedades da distribuição normal que é bastante usada na literatura especializada. Conforme demonstrado pelos autores em foco, estimativas isoladas das equações (5) e (6) pelo método usual de Mínimos Quadrados Ordinários (MQO) produzem parâmetros tendenciosos uma vez que os valores condicionais esperados das citadas equações resultam em:

$$
\begin{array}{ll}
E\left[S_{i}^{\text {fnc }} \mid D=0\right]=\eta_{0}+E\left[\varepsilon_{0 \mathrm{i}} \mid D=0\right], \\
E\left[S_{i}^{\text {fc }} \mid D=1\right]=\eta_{1}+E\left[\varepsilon_{1 i} \mid D=1\right],
\end{array}
$$

Onde $E\left[\varepsilon_{0 \mathrm{i}} \mid \mathrm{D}=0\right] \neq 0$ e $E\left[\varepsilon_{1 \mathrm{i}} \mid \mathrm{D}=1\right] \neq 0$ e $\eta_{0}$ e $\eta_{1}$ representam esperanças condicionais dos termos não estocásticos das respectivas equações.

Sob a hipótese de que os termos estocásticos das equações (5), (6) e (7) seguem uma distribuição normal multivariada, Heckman (1979) demonstra que as funções de controle (variáveis omitidas) $E\left[\varepsilon_{0 \mathrm{i}} \mid \mathrm{D}=0\right] \neq 0$ e $\mathrm{E}\left[\varepsilon_{1 \mathrm{i}} \mid \mathrm{D}=1\right] \neq 0$ podem

2 É possível demonstrar que $\phi=\delta\left(\alpha_{1}-\alpha_{0}\right), \pi=\left[\delta \beta_{1},-\delta \beta_{0}, \delta \theta_{1},-\delta \theta_{0}, \mu\right], \mathrm{W}_{\mathrm{i}}=\left[\mathrm{S}_{1 \mathrm{i}}{ }^{\mathrm{p}}, \mathrm{S}_{\mathrm{Oi}}{ }_{\mathrm{p}}, \mathrm{X}_{\mathrm{ii}}, \mathrm{X}_{\mathrm{oi}}, \mathrm{Z}_{\mathrm{i}}\right]$ e $\epsilon_{\mathrm{i}}=\delta\left(\varepsilon_{1 \mathrm{i}}{ }^{-}\right.$ $\left.\varepsilon_{0 i}\right)+v_{i}$. Conforme ressaltam Toomet e Henningsen (2008), uma condição necessária para a identificação dos parâmetros do modelo em foco requer que haja ao menos uma variável presente no vetorque não esteja incluída nos vetores e (variável instrumental de restrição de exclusão). 
ser estimadas respectivamente por $\lambda_{0}=\frac{-f\left(\hat{\phi}+W_{i} \hat{\pi}\right)}{1-F\left(\hat{\phi}+W_{i} \hat{\pi}\right)}$ e $\lambda_{1}=\frac{f\left(\hat{\phi}+W_{i} \hat{\pi}\right)}{F\left(\hat{\phi}+W_{i} \hat{\pi}\right)}$, conhecidas como taxas inversas de Mills (TOOMET; HENNINGSEN, 2008). Vale notar que $\hat{\phi}+W_{i} \hat{\pi}$ é a predição linear da equação (7), estimada por um probit em primeiro estágio. Já $f$ e $F$ são, em sequência, a função de densidade normal e função acumulada de densidade normal.

Ademais, é possível obter estimativas consistentes dos parâmetros das equações (5) e (6) - inclusive os coeficientes de persistência intergeracional de educação, $\beta_{0}$ e $\beta_{1}$ - regredindo, em segundo estágio, as últimas com os controles $\lambda_{0}$ e $\lambda_{1}$ na lista de covariadas. Portanto, as expectativas condicionais, com parâmetros corrigidos para viés de seleção amostral, são dadas por:

$$
E\left[S_{i}^{f n c} \mid D=0\right]=\hat{\alpha}_{0}+\hat{\beta}_{0} S_{0 i}^{p}+\hat{\theta}_{0}{ }^{\prime} X_{0 i}-\hat{\sigma}_{0} \hat{\rho}_{\epsilon 0} \lambda_{0}
$$

e

$$
E\left[S_{i}^{f c} \mid D=1\right]=\hat{\alpha}_{1}+\hat{\beta}_{1} S_{1 i}^{p}+\hat{\theta}_{1}^{\prime} X_{1 i}+\hat{\sigma}_{1} \hat{\rho}_{\epsilon 1} \lambda_{1}
$$

Onde $\hat{\alpha}_{0}, \hat{\alpha}_{1}, \hat{\beta}_{0}, \hat{\beta}_{1}, \hat{\theta}_{0}{ }^{\prime}$ e $\hat{\theta}_{1}{ }^{\prime}$ são valores estimados dos coeficientes e vetores de coeficientes das equações (5) e (6); $\hat{\sigma}_{0}$ e $\hat{\sigma}_{1}$ são estimativas dos desvios-padrão dos respectivos termos estocásticos $\varepsilon_{0 \mathrm{i}}$ e $\varepsilon_{1 \mathrm{i}}$ e $\hat{\rho}_{\epsilon 0}$ e $\hat{\rho}_{\epsilon 1}$ estimativas dos coeficientes de correlação linear entre termos randômicos não observados.

Uma vez que $\lambda_{0}$ e $\lambda_{1}$ representam funções de controle (variáveis omitidas) para seleção amostral, seus verdadeiros valores são desconhecidos. Nesse contexto, Heckman (1979) demonstra como obter valores consistentes para $\hat{\sigma}_{0}, \hat{\sigma}_{1}, \hat{\rho}_{\epsilon 0}$ e $\hat{\rho}_{\epsilon 1}$ e matrizes de covariância dos parâmetros ajustadas para inclusão das taxas inversas de Mills nas equações supracitadas. ${ }^{3}$ Ademais, vale observar, a partir das equações anteriores, que valores $\hat{\rho}_{\epsilon 0}>0$ e $\hat{\rho}_{\epsilon 1}>0$ estatisticamente significativos, por exemplo, indicam que seleção positiva (negativa) em atributos não observados para filhos corresidentes (não corresidentes), ou seja, uma pessoa selecionada no grupo de corresidentes (não corresidentes) teria, em média, um valor esperado de capital humano (anos de estudo) superior (inferior) a um indivíduo aleatoriamente identificado na amostra.

\subsubsection{Identificação}

Uma hipótese necessária para a estimativa não tendenciosa (identificação) dos parâmetros do modelo de mudança endógena de regime é a chamada restrição de exclusão (HECKMAN; NAVARRO-LOZANO, 2004), isto é, a existência de

3 Para mais detalhes, vide também Toomet e Henningsen (2008). 
ao menos uma variável $Z_{\mathrm{i}} \subset \mathrm{W}_{\mathrm{i}}$ na equação de seleção (7) que é independentedos termos não observados $\varepsilon_{0 \mathrm{i}}$ e $\varepsilon_{1 \mathrm{i}}$ e que não pertença às covariadas das equações de resultado (5) - (6) $Z_{\mathrm{i}} \notin \mathrm{X}_{\mathrm{oi}}, \mathrm{X}_{\mathrm{ii}}$. Em outras palavras, a identificação do efeito da mudança de regime (efeito do tratamento) requer a presença de informação adicional (instrumento $Z_{\text {i }}$ ) que mude o estado de tratamento, mas que não o valor médio da variável de resultado $4\left(\mathrm{~S}_{i}^{\text {fc }}\right.$ e $\left.\mathrm{S}_{i}^{\text {fnc }}\right)$.

Assumindo o pressuposto de restrição de exclusão $\left(Z_{\mathrm{i}} \perp \varepsilon_{0 \mathrm{i}}, \varepsilon_{1 \mathrm{i}} \mid \mathrm{X}_{\mathrm{oi}} \mathrm{X}_{\mathrm{ii}}\right)$, juntamente com as hipóteses de monotonicidade do estado de tratamento em relação ao instrumento $Z_{\mathrm{i}}$ (o estado de regime potencial não diminui com o instrumento) ${ }^{5}$ e que $Z_{\mathrm{i}}$ tem impacto sobre o regime de seleção (há uma subpopulação de indivíduos - compliers - que reagem diretamente à mudança do instrumento), Huber e Mellace (2015) derivam quatro restrições de desigualdade que permitem testar a hipótese de validade do instrumento $Z_{\mathrm{i}}$ :

$$
\begin{gathered}
H_{0}:\left(\begin{array}{c}
E\left(S^{f c} \mid X, Z=1, D=1, S^{f c} \leq S_{q}\right)-E\left(S^{f c} \mid X, Z=0, D=1\right) \\
E\left(S^{f c} \mid X, Z=0, D=1\right)-E\left(S^{f c} \mid X, Z=1, D=1, S^{f c} \geq s_{1-q}\right) \\
E\left(S^{f n c} \mid X, Z=0, D=0, S^{f n c} \leq s_{r}\right)-E\left(S^{f n c} \mid X, Z=1, D=0\right) \\
E\left(S^{f n c} \mid X, Z=1, D=0\right)-E\left(S^{f n c} \mid X, Z=0, D=0, S^{f n c} \geq s_{1-r}\right)
\end{array}\right) \equiv \\
\left(\begin{array}{l}
\gamma_{1} \\
\gamma_{2} \\
\gamma_{3} \\
\gamma_{4}
\end{array}\right) \leq\left(\begin{array}{l}
0 \\
0 \\
0 \\
0
\end{array}\right),
\end{gathered}
$$

Onde E é a expectativa condicional; $q$ é a proporção observada de indivíduos sempre selecionados (subpopulação de pessoas que se selecionam enquanto filhos corresidentes independente de $Z_{\mathrm{i}}$ - always takers); $r$ é a proporção observada de indivíduos nunca selecionados (subpopulação de indivíduos que assumem a condição de não corresidentes independente de $Z_{\mathrm{i}}$ - never takers); $s_{q}$ é o quantil da variável de resultado (anos de estudo) condicionado à probabilidade $q$ e $s_{r} \mathrm{o}$ quantil $r$ da variável de resultado (anos de estudo).

As desigualdades $\gamma_{1}, \gamma_{2}, \gamma_{3}$ e $\gamma_{4}$, correspondem a intervalos de variação identificados para o valor médio da variável de resultado para subpopulações de indivíduos sempre selecionados/tratados - always takers - $\left(\gamma_{1}, \gamma_{2}\right)$ e para subpopulação de pessoas nunca selecionadas (sempre controle) - never takers - $\left(\gamma_{3}, \gamma_{4}\right)$ sob a hipótese

4 Conforme demonstrado por Toomet e Henningsen (2008), a hipótese de restrição de exclusão não é suficiente para assegurar a identificação do modelo em destaque, visto que, se possuir uma grande variabilidade, os parâmetros podem ser corretamente estimados por não linearidades nas funções de controle $\lambda_{0}$ e $\lambda_{1}$. Todavia, o uso de variáveis instrumentais adequadas enquanto restrições de exclusão auxiliam na identificação dos parâmetros do modelo de seleção endógena.

De acordo com Huber e Mellace (2015), esse pressuposto equivale à inexistência do grupo chamado defiers, isto é, um subgrupo da população que só assume o estado de tratamento (corresidência) quando o valor do instrumento $Z_{\mathrm{i}}$ diminui. 
nula conjunta $\left(\mathrm{H}_{0}\right)$ de independência de $\mathrm{Z}_{\mathrm{i}}$ (restrição de exclusão), monotonicidade do tratamento e existência de compliers.

Para testar conjuntamente as restrições de desigualdades propostas em (8), Huber e Mellace (2015) empregam o método de Chen e Szroeter (2014) e métodos baseados em reamostragens bootstrap propostos por Bennett (2009), que produzem $\mathrm{p}$-valores robustos em amostras finitas. ${ }^{6}$

Huber e Mellace (2015) também demonstram que as restrições de desigualdade presentes em (8) podem resultar em restrições de igualdade mediante hipóteses mais fortes acerca de dominância de valor médio da variável de resultado entre os grupos always takers e compliers e never takers e compliers. Nesse caso mais restrito, os referidos autores sugerem que a validade de $Z_{\mathrm{i}}$ pode ser averiguada a partir de testes t-student para as seguintes diferenças de médias:

$$
H_{0}:\left(\begin{array}{c}
E\left(S^{f c} \mid X, Z=1, D=1\right)-E\left(S^{f c} \mid X, Z=0, D=1\right) \\
E\left(S^{f n c} \mid X, Z=1, D=0\right)-E\left(S^{f n c} \mid X, Z=0, D=0\right)
\end{array}\right) \equiv\left(\begin{array}{l}
\overline{\gamma_{1}} \\
\overline{\gamma_{2}}
\end{array}\right)=\left(\begin{array}{l}
0 \\
0
\end{array}\right)
$$

\section{Dados}

Os dados utilizados neste trabalho são oriundos da Pesquisa Nacional por Amostra de Domicilio (PNAD) de 1996. Esta tem sido a pesquisa mais usada para se investigar a dinâmica intergeracional entre atributos de pais e filhos. Isto se deve ao fato de se poderem cruzar informações acerca dos pais das pessoas entrevistadas na condição de chefia familiar através de seu suplemento social. Em especial, o interesse recai no cruzamento das informações sobre o nível de instrução dos pais e dos filhos, assim como em alguns atributos socioeconômicos dos entrevistados, a saber: gênero, raça, localização, atividade econômica e condição no domicílio.

Com o intuito de se comparar alguns resultados empíricos, sobretudo no tocante às evidências elencadas por Ferreira e Veloso (2003), a amostra foi selecionada de acordo com certos critérios empregados pelos últimos autores. Primeiro, foram consideradas apenas as pessoas do sexo masculino que, na data da pesquisa, se achavam na faixa etária dos 25 aos 64 anos de idade. ${ }^{7}$ Desse total, excluíram-se aqueles que não informaram sua própria escolaridade e a do seu pai. Ademais, os valores da escolaridade dos pais foram compatibilizados de acordo com o mesmo critério empregado no estudo de Ferreira e Veloso (2003). A Tabela 4, no Apêndice A, fornece uma descrição detalhada de todas as variáveis selecionadas.

Em particular, as variáveis total de outras famílias no domicílio e total de outras famílias no domicílio ao quadrado foram usadas com restrições de exclusão (instru-

$6 \quad$ Para detalhes desses algoritmos de teste, vide Chen e Szroeter (2014) e Huber e Mellace (2015).

7 Há duas justificativas importantes para essa filtragem. Primeiro, a seleção aqui adotada é semelhante à empregada em vários estudos internacionais sobre o tema. Segundo, o recorte pela referida faixa etária procura captar pessoas que já alcançaram determinado ciclo no processo de acumulação de capital humano. 
mentos - ) no modelo empírico (5)-(7), de modo que apenas são incluídas como covariadas na equação de seleção (7). Conforme ressaltado na revisão da literatura, vários estudos apontam a relação entre decisão de convivência com os pais na vida adulta com custos de moradia (GIANNELLI; MONFARDINI, 2003; COBB-CLARK; GORGENS, 2014). A hipótese adotada neste trabalho é que custos ou benefícios financeiros/psicológicos não diretamente observados e envolvidos no processo de convivência estão relacionados com a quantidade de outras famílias conviventes no domicílio. Destarte, a inclusão de um termo quadrático procura averiguar se há uma relação não linear entre tal variável e a probabilidade de seleção do indivíduo adulto enquanto dependente de seu pai no domicílio.

A partir dos recortes supracitados, os filhos foram separados em dois grupos: (i) filhos não cor residentes ou "independentes" - aqueles que se declararam responsáveis pelo domicílio ou cônjuge, totalizando uma subamostra idêntica a usada por Ferreira e Veloso (2003), isto é, 43.772 indivíduos e (ii) filhos corresidentes ou "dependentes" - aqueles que ainda se encontravam residindo com seus pais no domicílio, ou seja, 5.143 pessoas. ${ }^{8}$ Portanto, a amostra final foi de 48.915 filhos, $10,5 \%$ dependentes e $89,5 \%$ emancipados.

Um aspecto que deve ser destacado é que a PNAD é caracterizada por um plano amostral complexo, o qual envolve estratificação e conglomeração (unidades amostrais com diferentes probabilidades de seleção entre estratos). Ao contrário da maioria dos estudos realizados na literatura nacional sobre o tema, neste trabalho são considerados não apenas os pesos das unidades amostrais, mas também informações sobre estratos e unidades primárias de amostra (plano amostral) no cálculo de estatísticas de medida central, dispersão e parâmetros (erros-padrão) de regressões. Nesse sentido, além de fornecer uma visão geral sobre o processo de amostragem da PNAD, Silva, Pessoa e Lila (2002) também ressaltam que estimativas de médias, totais e/ou taxas para a população não são tendenciosas quando são ponderadas pelos pesos das unidades amostrais. Por outro lado, o cálculo de estatísticas de dispersão (variância, desvio-padrão, erro-padrão, etc.), importantes no processo de inferência, necessita de informações adicionais acerca do planejamento amostral, caso contrário serão medidas viciadas. ${ }^{9}$

8 Os atributos dos filhos residentes no domicílio foram relacionados com a escolaridade do pai (chefe de domicílio) a partir da identificação do código do domicílio e da unidade da federação.

9 Os estimadores de variância comumente usados em amostragens aleatórias simples com reposição são lineares nos dados e baseiam-se na hipótese de independência e de igualdade de distribuição (iid). Quando se considera um plano amostral complexo, tais hipóteses não se mantêm e os estimadores tradicionais não são válidos. Ao contrário, a obtenção de estatísticas não tendenciosas envolve o cálculo de estimadores não lineares nos dados. Nesse contexto, o estimador de variância com linearização de Taylor é bastante empregado. Para mais detalhes, ver Pessoa e Costa (2013). 
A Tabela 1 apresenta as estatísticas descritivas das amostras selecionadas segundo a condição domiciliar dos filhos. No caso das variáveis dicotômicas, são apresentadas apenas as categorias não omitidas, sendo que nesse caso a média equivale à proporção em relação à categoria omitida. Para destacar a importância de incorporação do plano amostral complexo da PNAD, as médias e erros-padrão foram calculados considerando um plano amostral simples (PAS) - método ingênuo - e o plano amostral complexo (PAC) efetivo da pesquisa (incorporando pesos das unidades amostrais, estratos e unidades primárias da amostra). A métrica que mensura o efeito do plano amostral (EPA) é dada pela razão entre o estimador de variância com PAC e o estimador de variância tradicional com PAS (PESSOA; COSTA, 2013). 


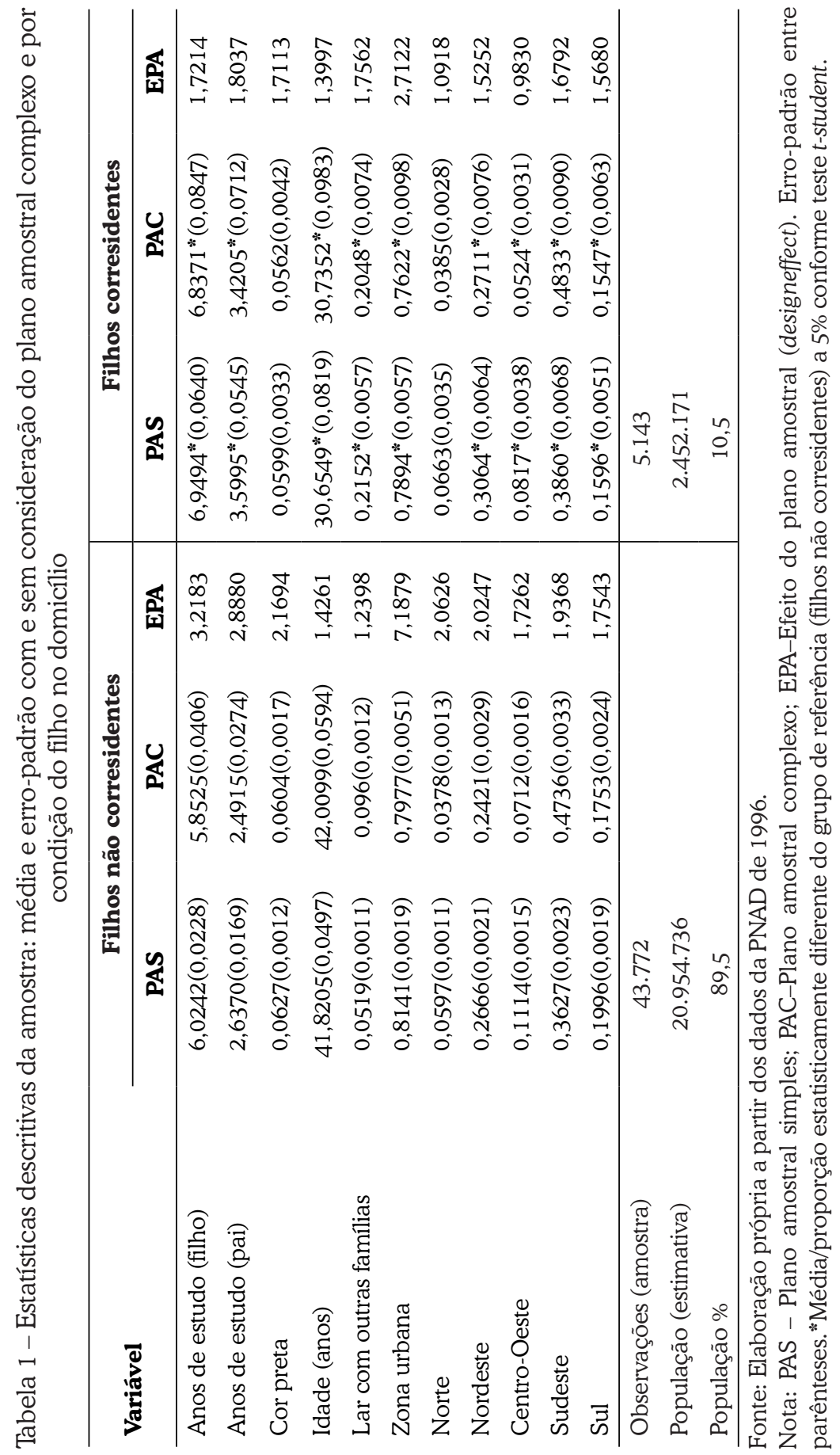


Os dados revelam diferenças importantes nas características pessoais dos dois grupos em foco. Cabe notar que as médias de instrução de filhos corresidentes (dependentes no domicílio) e de seus pais superam aquelas registradas para o grupo não corresidente (responsável ou cônjuge no domicílio). Outro atributo bastante distintivo é a idade. O filho emancipado típico tem, em média, 42 anos, isto é, 10 anos a mais que o filho dependente. Também chama a atenção a diferença na distribuição de filhos adultos conforme a convivência com outra família. Enquanto $20,1 \%$ dos filhos adultos dependentes dos pais viviam em domicílios com mais de uma família, apenas 4,9\% dos filhos emancipados se achavam nessa situação.

As estatísticas indicam que filhos não dependentes também se encontravam em domicílio com menor média de pessoas, sendo que $89,1 \%$ destes trabalhavam ou procuravam emprego (economicamente ativos) contra 79,8\% de filhos dependentes. Já distribuição dos dois grupos de filhos entre grandes regiões parece ser mais homogênea. Destaca-se apenas a maior participação relativa de filhos dependentes nas regiões Nordeste (27,1\% contra $24,2 \%$ de não corresidentes) e menor presença destes na região Sul (15,5\% contra 17,5\% de emancipados). Ao se cotejar as distribuições dos grupos por zona urbana e rural (omitida), percebe-se a menor presença de filhos dependentes, isto é, 76,2\% dos filhos corresidentes viviam no meio urbano em1996, enquanto $79,7 \%$ dos filhos não corresidentes moravam em área urbana.

Outro aspecto relevante diz respeito às estatísticas de erro-padrão (dispersão), que, em geral, são subestimadas ao se ignorar a natureza complexa da amostragem da PNAD. Os valores do EPA são, em sua maioria, superiores à unidade, isto é, indicam viés considerável nas medidas obtidas sem a incorporação de pesos e plano da amostra.

\section{Resultados}

Esta seção é dedicada à apresentação e discussão dos resultados empíricos deste estudo. Ela está dividida em duas subseções. Na primeira são apresentados os achados a partir da abordagem não paramétrica de matrizes de transição de Markov, enquanto na segunda são discutidas as evidências produzidas a partir da estimação de um modelo paramétrico de determinação conjunta de corresidência com os pais e acumulação de capital humano.

\subsection{Análise de matrizes de transição}

Nesta subseção são apresentados e discutidos resultados iniciais com base na exploração de estimativas não paramétricas de probabilidades de persistência intergeracional de educação a partir de algumas dimensões selecionadas. Os dados 
apresentados a seguir referem-se às probabilidades estimadas a partir da diagonal principal na matriz de transição markoviana (2) e os intervalos de confiança (95\%) produzidos a partir do método proposto por Sison e Glaz (1995) para proporções multinomiais.

A Figura 1 registra as probabilidades de persistência educacional dos filhos considerando diferentes faixas de escolaridade do pai e a corresidência com os pais na fase adulta, ou seja, revela as probabilidades condicionadas do filho permanecer com o mesmo nível de instrução do pai.

Figura1 - Brasil - Probabilidades de persistência educacional segundo a instrução do pai e por condição do filho no domicílio

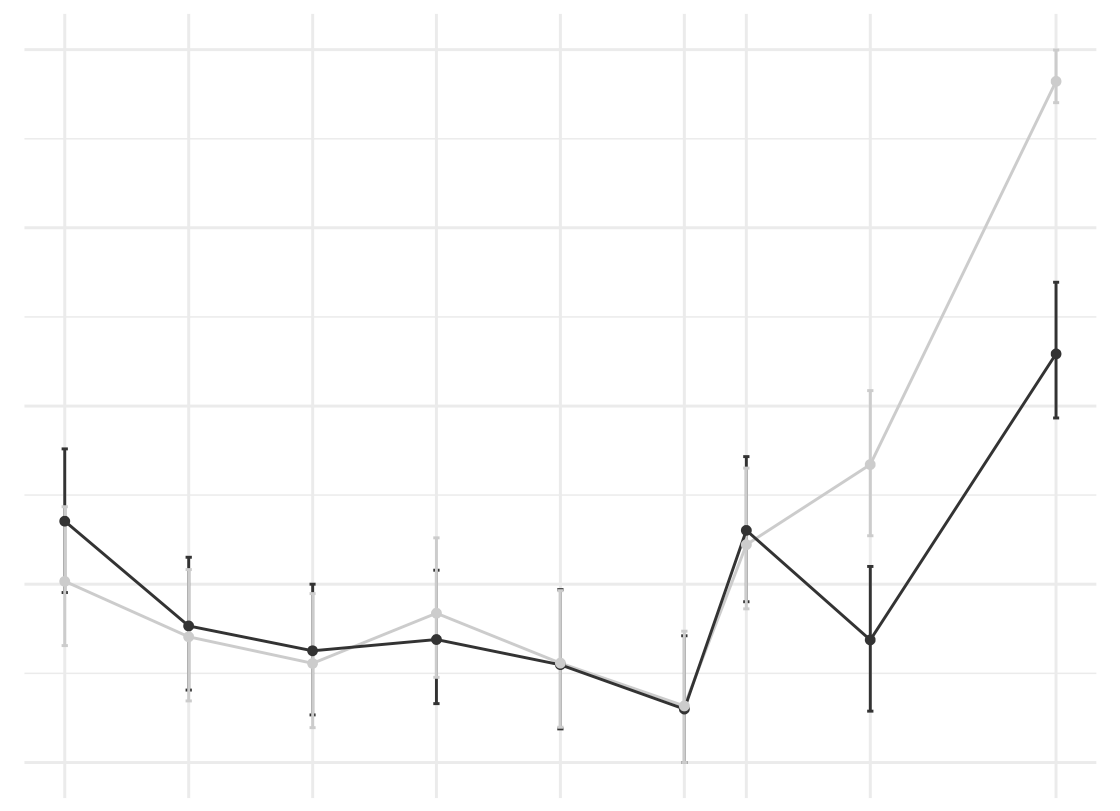

Fonte: Elaboração própria a partir dos dados da PNAD de 1996.

Nota: Dados ponderados pelo peso amostral.

É importante observar que o estoque de capital humano dos pais parece gerar diferenças importantes na mobilidade educacional dos filhos no Brasil, sobretudo nos extremos da distribuição da instrução, em que há maior diferença. Note-se, um filho de pai com formação superior registra $57 \%$ de chance de acumular esse 
mesmo nível de instrução em caso de emancipação e 95\% se corresidir com os pais quando adulto, caso em que a condição de corresidência discrimina os resultados sem sobreposição de intervalos de confiança.

Por outro lado, nota-se que um filho de pai analfabeto tem entre $23 \%$ e $43 \%$ de probabilidade de permanecer analfabeto, caso não resida com o mesmo na fase adulta, e entre $16 \%$ e $35 \%$, caso contrário. Tais intervalos não registram diferença estatística se comparados a outros estimados para pais com formação abaixo do nível superior. Não obstante, é possível observar dois outros picos importantes de probabilidade de persistência de educação, especialmente em relação aos pais com 6 anos de instrução ou com 11 anos. Tais resultados possivelmente estão relacionados ao ciclo de conclusão do ensino fundamental e médio, em que muitas pessoas optam por deixar a escola.

A condição socioeconômica das famílias pode ser determinada por uma série de fatores pessoais, familiares e contextuais. É fato muito conhecido na literatura que a condição social no Brasil é historicamente associada à raça do indivíduo e constitui-se uma importante restrição para o progresso econômico, sobretudo para as pessoas não brancas (FERREIRA; VELOSO, 2003; FIGUEIRÊDO; NETTO JÚNIOR; PÔRTO JÚNIOR, 2007). Na Figura 2 são apresentadas as probabilidades de persistência educacional dos filhos condicionadas à cor da pele, à corresidência com os pais na vida adulta e à própria educação dos pais. 
Figura2 - Brasil - Probabilidades de persistência educacional segundo a instrução do pai e por cor da pele

(a) Não corresidente

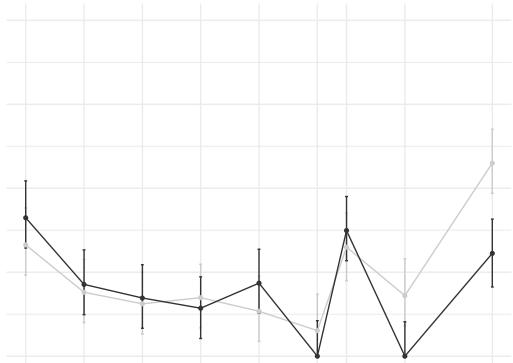

(b) Corresidente

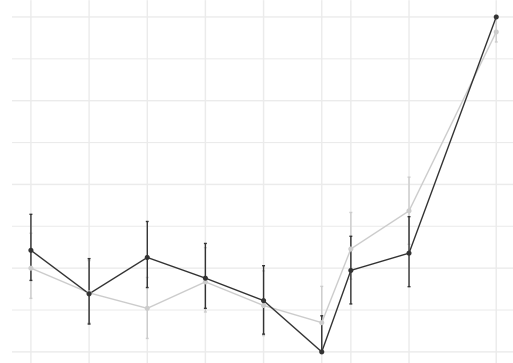

Fonte: Elaboração própria a partir dos dados da PNAD de 1996.

Nota: Dados ponderados pelo peso amostral.

Os dados não apontam diferença estatística entre probabilidades de persistência por cor da pele, visto que há sobreposição da maioria dos intervalos de confiança por nível de instrução do pai. ${ }^{10}$ Todavia, vale lembrar que, embora não se esteja ponderando outras variáveis relacionadas à determinação da mobilidade intergeracional, há evidência de maiores probabilidades de persistência quando o pai registra alto nível de escolaridade, sobretudo para filhos corresidentes. Vale observar que neste caso há maior chance de persistência para filhos de cor não preta (entre $48,5 \%$ e $67,6 \%$ ) comparados a filhos de cor preta (entre $20,6 \%$ e 40,8\%).

O contexto regional pode moldar o conjunto de oportunidades que indivíduos se defrontam ao longo da vida, criando, portanto, importantes desigualdades de oportunidades. A Figura 3 registra probabilidades de persistência educacional de filhos adultos considerando duas regiões brasileiras bastante distintas na ótica institucional e econômica: Nordeste e Sudeste. Enquanto a primeira é conhecida pela elevada incidência de pobreza, baixa educação e desigualdade de renda, a segunda concentra os maiores parques industriais e instituições financeiras, respondendo por mais de $50 \%$ da riqueza produzida no Brasil.

Como pode ser observado, um filho de pai analfabeto no Nordeste é extremamente desfavorecido se cotejado a outro residente na região Sudeste. No grupo de não corresidentes, um filho de pai analfabeto que vive na região Nordeste tem chance entre $44,9 \%$ e $64,6 \%$ de permanecer analfabeto, enquanto se o mesmo

10 Algumas estimativas de probabilidade são imprecisas em razão de frequências nulas na matriz de transição. 
vivesse na região Sudeste tal intervalo de chance seria de 12,2\% a 32,0\%. Já entre corresidentes, estes intervalos são respectivamente de 32,6\% a 52,4\% e de 3,4\% a $22,1 \%$. Ainda no grupo de corresidentes se constata uma diferença significativa de intervalos de probabilidade de persistência para filhos de pai com ensino médio completo entre as regiões em destaque. Nesse caso, os dados revelam que um filho de pai com 11 anos completos de estudo que reside no Nordeste tem intervalo de persistência intergeracional de $37,1 \%$ a 56,5\%, contra o intervalo de $14,2 \%$ a $33,9 \%$ em caso de residência no Sudeste.

A Figura 4 reporta estimativas de probabilidades de persistência intergeracional de educação por condição do filho adulto no domicílio e segundo coortes de nascimento. Os resultados não mostram diferenças significativas de persistência entres os grupos de filhos corresidentes e não corresidentes, embora seja possível constatar uma tendência de menor persistência, em média, para a geração de filhos nascidos no período mais recente (1962-1971) se comparada à coorte inicial (1932-1941). Esses resultados são consistentes com aqueles já demonstrados por Ferreira e Veloso (2003), ao indicarem a redução da persistência intergeracional da educação nas gerações mais recentes.

Figura3 - Brasil - Probabilidades de persistência educacional segundo a instrução do pai e por condição do filho no domicílio e regiões selecionadas

(a) Não corresidente

(b) Corresidente
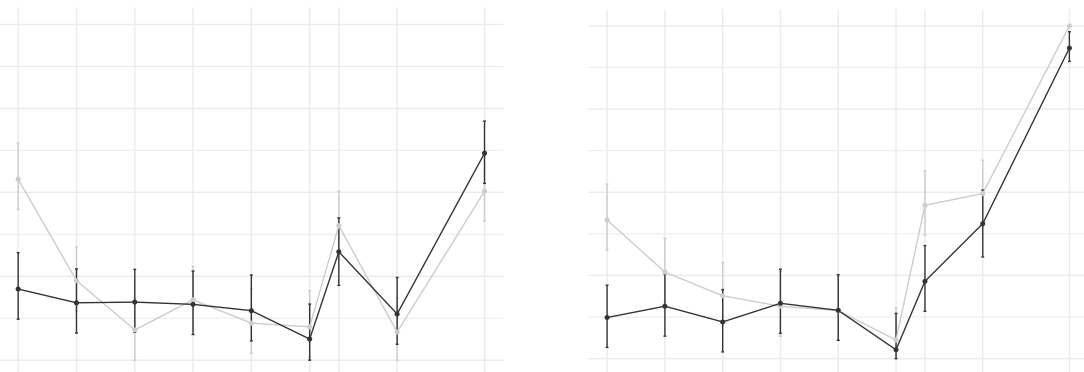

Fonte: Elaboração própria a partir dos dados da PNAD de 1996.

Nota: Dados ponderados pelo peso amostral. 
Figura4 - Brasil - Probabilidades de persistência educacional segundo coorte de nascimento e por condição do filho no domicílio (apenas filhos de pais analfabetos)

Fonte: Elaboração própria a partir dos dados da PNAD de 1996.

Nota: Dados ponderados pelo peso amostral.

Embora as estimativas de probabilidade de persistência intergeracional de educação registradas nas figuras anteriores tenham sido obtidas de forma bastante flexível com uso de matrizes markovianas e sinalizado correlações importantes, elas não ponderam simultaneamente outros fatores (observados/não observados) importantes para a determinação da mobilidade intergeracional, assim como não resumem a questão da persistência (mobilidade) em um único valor (índice). Nesse sentido, os resultados apresentados a seguir trazem mais rigor e luz à discussão de evidências sobre mobilidade intergeracional de educação no Brasil.

\subsection{Análise Econométrica}

Esta subseção se destina a apresentação dos resultados dos modelos empíricos. A análise é aqui direcionada ao teste de duas hipóteses: i) A ausência dos filhos corresidentes na estimação da persistência intergeracional educacional gera coeficientes tendenciosos? (ii) De que forma a decisão de corresidir está associada com variáveis de estrutura familiar e de local de residência? 


\subsubsection{Estimativas de Coeficientes de Persistência Intergeracional de Educação}

A Tabela 2 registra resultados de regressões lineares referentes à equação de persistência intergeracional (3) considerando amostras separadas pela condição do filho adulto no domicílio. As regressões (1) e (2) não consideram pesos amostrais, estratos e unidades primárias da amostra da PNAD de 1996, enquanto as regressões (3) e (4) incorporam o plano amostral complexo (inclusive pesos) nas estimativas de coeficientes e erros-padrão.

Tabela 2 - Regressões lineares - variável dependente: anos de estudo do filho

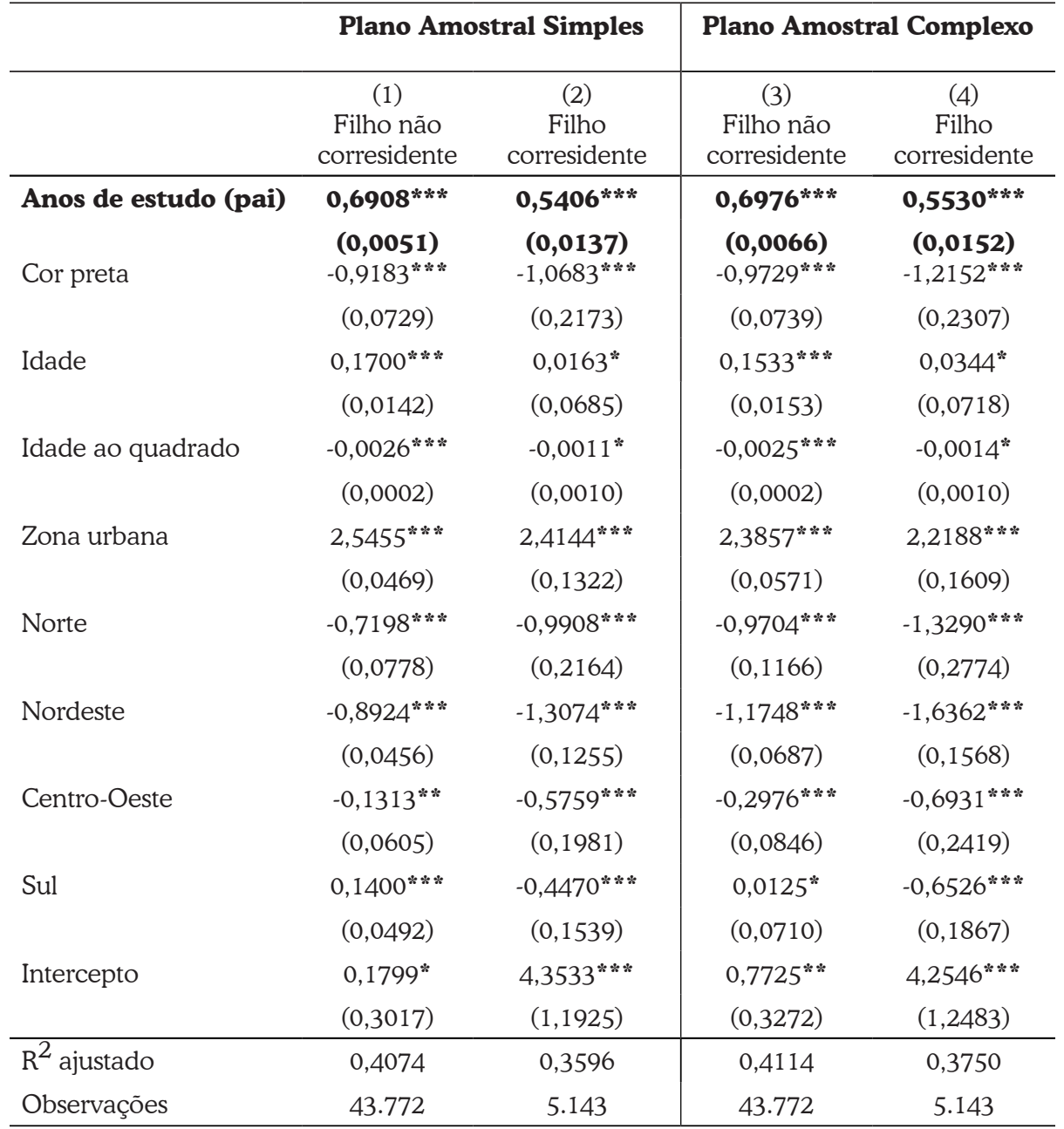

Fonte: Elaboração própria a partir dos dados da PNAD de 1996.

Nota: Erros-padrão robustos à heterocedasticidade entre parênteses. * * Estatisticamente significantea $1 \%$. * Estatisticamente significante a 5\%. "Estatisticamente significante a 10\%. 
Os resultados revelam que o coeficiente de persistência (mobilidade) intergeracional é relativamente menor (maior) para filhos dependentes dos pais no domicílio. Enquanto cada ano de estudo a mais de um pai gera, em média, um incremento de 0,69 anos de estudo $\left(\beta_{0}\right)$ para um filho chefe (cônjuge) no domicílio, tal acréscimo é de apenas 0,55 anos de estudo $\left(\beta_{1}\right)$ para um filho dependente do pai no domicílio. O primeiro coeficiente estimado é similar ao obtido por Ferreira e Veloso (2003), porém considerando as informações do plano amostral complexo da PNAD. Já o segundo coeficiente chama a atenção para uma possível correlação entre mobilidade intergeracional de educação e convivência do filho com pai na vida adulta; fato ainda não devidamente explorado na literatura especializada.

Considerando as regressões (1) e (2) com as registradas nas colunas (3) e (4), percebe-se que a omissão do plano amostral complexo (inclusive pesos amostrais) produz estimativas tendenciosas para a maioria dos coeficientes, além de erros-padrão subestimados em geral. Tal fato é relevante uma vez que a literatura especializada no Brasil não tem dado a devida atenção a essa questão técnica.

Algumas características contribuem de forma diferenciada para a instrução dos filhos a depender de sua condição no domicílio. Este é caso da cor da pele, da idade e da área de residência. Os coeficientes estimados na tabela em foco sugerem que um filho adulto, corresidente e de cor preta tem, em média, 1,21 anos de estudo a menos que um filho de outra cor (categoria de referência) e na mesma condição domiciliar. No caso de um filho não corresidente e de cor preta, sua instrução é inferior à de um filho adulto de outra cor em 0,97 anos de estudo. Também é possível constatar que aumento da idade favorece a acumulação de capital humano do filho, especialmente para aqueles que não dependem do pai no domicílio. Os filhos residentes no meio urbano são, em média, mais instruídos que os residentes na zona rural (categoria omitida), enquanto aqueles residentes nas regiões Norte, Nordeste, Centro-Oeste e Sul, obtiveram menor instrução, em média, que filhos moradores da região Sudeste (categoria base), especialmente, quando se consideram filhos que vivem com os pais.

Embora os resultados apresentados forneçam indícios de diferenças de persistência (mobilidade) intergeracional de educação por condição do filho adulto no domicílio, eles não permitem inferir em que medida as decisões de corresidência com os pais e de acumulação de capital humano dos filhos estão associadas. Nesse sentido, os dados dispostos na Tabela 3 agregam mais informações no que se refere a essa questão. As colunas (1) e (2) referem-se, respectivamente, às regressões lineares realizadas em segundo estágio para as equações (5) e (6) em queo grau de instrução do filho é variável dependente. Elas também incorporam as variáveis de controle e para viés de seleção amostral (obtidas em primeiro estágio) como covariadas. Já a coluna (3) reporta os resultados da estimativa da equação reduzida (7) por um probit em primeiro estágio (variável de resposta bi- 
nária: 1 se o filho é corresidente - dependente do pai; 0 se o filho é chefe/cônjuge no domicílio).

As evidências reportadas na Tabela 3 reforçam aquelas encontradas nas regressões preliminares presentes na tabela anterior, uma vez que há diferença estatística entre os coeficientes de persistência intergeracional de educação $\beta_{0}$ e $\beta_{1}$ de acordo com a condição do filho no lar, com menor (maior) indicador de persistência (mobilidade) intergeracional para o filho corresidente. Nesse aspecto, vale observar dois pontos. Primeiro, enquanto o coeficiente de persistência para um filho típico não corresidente é de 0,71, a estimativa obtida para um filho corresidente é de 0,56 . Tais valores são ligeiramente superiores àqueles produzidos sob a hipótese de independência das decisões de corresidência e de acumulação de capital humano. Segundo, os coeficientes associados às variáveis de controle $\lambda 0$ e $\lambda 1$ são positivos e estatisticamente significativos a $1 \%$ e, por conseguinte, os coeficientes de correlação $\hat{\rho}_{\epsilon 0}$ e $\hat{\rho}_{\epsilon 1}$ também são positivos. Tais resultados sugerem um processo endógeno de autosseleção positiva (negativa) de filhos na condição de corresidência (independência do pai), isto é, um filho que convive com o pai na vida adulta tem, em média, uma escolaridade superior à outra pessoa aleatoriamente selecionada na amostra, enquanto um filho independente (chefe ou cônjuge de domicílio) registra um grau de instrução média inferior na mesma comparação. Destarte, os coeficientes de persistência obtidos na Tabela 2 são tendenciosos.

\subsubsection{Determinantes da Decisão de Corresidência}

No tocante às demais variáveis, a maioria das correlações já observadas nas regressões ingênuas foipreservada. Ou seja, maior escolaridade, em média, para filhos adultos residentes no meio urbano em relação aos moradores do meio rural; menor instrução média de moradores de outras regiões comparadas ao Sudeste; menor acumulação de capital humano para pessoas de cor preta se comparadas a outras cores de pele. No entanto, cabe ressaltar que, após o controle para viés de seleção amostral, os coeficientes da equação de transmissão intergeracional para filhos não corresidentes - coluna (1) - apresentaram mudanças significativas se comparados aos observados nas regressões da Tabela 2. Por exemplo, a correção de viés para o grupo de corresidentes alterou não apenas a magnitude do coeficiente associado à variável idade, mas seu sinal, que passou de positivo para negativo.

Conforme observado na coluna (3) da Tabela 3, há uma correlação direta entre a probabilidade de o filho permanecer sob a dependência do pai na vida adulta e a escolaridade deste último. Ou seja, um ano amais de estudo do pai aumenta a chance de o filho corresidir com ele em 0,37 p.p. ${ }^{11}$ o que está em linha com os

11 Para dispor os resultados de forma mais clara possível, os coeficientes de efeitos marginais nas médias das covariadas estão registrados na Tabela A.3 do Apêndice. 
resultados encontrados por Giannelli e Monfardini (2003), Cobb-Clark e Gorgens (2014) e Sá et al. (2011). Por outro lado, residir no meio urbano, comparado à zona rural (categoria base), diminui a probabilidade de convivência com o pai em 3,1 p.p. Também chama a atenção a correlação entre decisão de corresidência e localização regional, em particular o caso do Centro-Oeste. Viver nesta região diminui a chance de um filho corresidir com pai na vida adulta em 4,3 p.p se comparado com uma pessoa residente na região Sudeste (categoria de referência). Já a idade apresenta uma relação não linear (convexa) com a probabilidade de corresidência com pai, reduzindo a chance de corresidência em 0,78 p.p para cada ano a mais de vida do filho. ${ }^{12}$

Tabela 3 - Regressões-Determinantes do grau de instrução e da corresidência do filho

\begin{tabular}{|c|c|c|c|}
\hline & \multicolumn{2}{|c|}{ Transmissão Intergeracional } & \multirow{2}{*}{$\begin{array}{c}\begin{array}{c}\text { Decisão de } \\
\text { corresidência }\end{array} \\
\text { Binária: filho } \\
\text { corresidente } \\
(\mathrm{d}=1) ; \text { filho não } \\
\text { corresidente }(\mathrm{d}=0)\end{array}$} \\
\hline Variável dependente & $\begin{array}{l}\text { Anos de estu- } \\
\text { do (filho não } \\
\text { corresidente) }\end{array}$ & $\begin{array}{c}\text { Anos de } \\
\text { estudo (filho } \\
\text { corresidente) }\end{array}$ & \\
\hline Covariadas & (1) & $(2)$ & (3) \\
\hline Anos de estudo (pai) & $\begin{array}{c}0,7136 * * * \\
(0,0054)\end{array}$ & $\begin{array}{c}0,5563 * * * \\
(0,0051)\end{array}$ & $\begin{array}{c}0,0277^{* * *} \\
(0,0030)\end{array}$ \\
\hline Cor preta & $\begin{array}{c}-0,9707 * * * \\
(0,0761)\end{array}$ & $\begin{array}{c}-1,2053 * * * \\
(0,0704)\end{array}$ & $\begin{array}{l}-0,0186^{*} \\
(0,0491)\end{array}$ \\
\hline Idade & $\begin{array}{c}-0,0646^{* * *} \\
(0,0181)\end{array}$ & $\begin{array}{l}0,0160 * \\
(0,0164)\end{array}$ & $\begin{array}{c}-0,1793 * * * \\
(0,0099)\end{array}$ \\
\hline Idade ao quadrado & $\begin{array}{l}-0,0004^{*} \\
(0,0002)\end{array}$ & $\begin{array}{c}-0,0013 * * * \\
(0,0002)\end{array}$ & $\begin{array}{c}0,0012^{* * *} \\
(0,0001)\end{array}$ \\
\hline Zona urbana & $\begin{array}{c}2,2653 * * * \\
(0,0491)\end{array}$ & $\begin{array}{c}2,1965 * * \\
(0,0463)\end{array}$ & $\begin{array}{c}-0,2318^{* * *} \\
(0,0306)\end{array}$ \\
\hline Norte & $\begin{array}{c}-1,0221 * * * \\
(0,0815)\end{array}$ & $\begin{array}{c}-1,3358 * * * \\
(0,0747)\end{array}$ & $\begin{array}{c}-0,1498 * * * \\
(0,0522)\end{array}$ \\
\hline Nordeste & $\begin{array}{c}-1,1917^{* * *} \\
(0,0472)\end{array}$ & $\begin{array}{c}-1,6302 * * * \\
(0,0437)\end{array}$ & $\begin{array}{l}-0,0647^{* *} \\
(0,0288)\end{array}$ \\
\hline Sul & $\begin{array}{l}-0,0779^{*} \\
(0,0521)\end{array}$ & $\begin{array}{c}-0,6685 * * * \\
(0,0485)\end{array}$ & $\begin{array}{c}-0,1587^{* * *} \\
(0,0350)\end{array}$ \\
\hline Centro-Oeste & $\begin{array}{c}-0,4700 * * * \\
(0,0640)\end{array}$ & $\begin{array}{c}-0,7340 * * * \\
(0,0615)\end{array}$ & $\begin{array}{c}-0,3198 * * * \\
(0,0418)\end{array}$ \\
\hline
\end{tabular}

12 Este cálculo considera o efeito marginal na média de idade na amostra total (40,8 anos). 
Transmissão Intergeracional Decisão de corresidência

\begin{tabular}{lccc}
\hline Variável dependente & $\begin{array}{c}\text { Anos de estu- } \\
\text { do (filho não } \\
\text { corresidente) }\end{array}$ & $\begin{array}{c}\text { Anos de } \\
\text { estudo (filho } \\
\text { corresidente })\end{array}$ & $\begin{array}{c}\text { Binária: filho } \\
\text { corresidente } \\
(\mathrm{d}=1) \text {; filho não } \\
\text { corresidente }(\mathrm{d}=0)\end{array}$ \\
\hline
\end{tabular}

\begin{tabular}{|c|c|c|c|}
\hline Covariadas & (1) & (2) & (3) \\
\hline \multirow[t]{2}{*}{ Outras famílias no domicílio } & & & $0,5191 * *$ \\
\hline & & & $(0,0215)$ \\
\hline \multirow[t]{2}{*}{ Outras famílias (ao quadrado) } & & & $-0,0297 * * *$ \\
\hline & & & $(0,0035)$ \\
\hline$\lambda_{0}$ & $\begin{array}{c}2,8753 * * * \\
(0,1345)\end{array}$ & & \\
\hline$\lambda_{1}$ & & $\begin{array}{c}0,2177^{* * *} \\
(0,0656)\end{array}$ & \\
\hline \multirow[t]{2}{*}{ Intercepto } & $6,5462 * * *$ & $4,5084 * * *$ & $3,5908 * * *$ \\
\hline & $(0,4202)$ & $(0,3137)$ & $(0,1816)$ \\
\hline $\mathrm{R}^{2}$ ajustado & 0,4137 & 0,3762 & \\
\hline Observações & 43.772 & 5.143 & 48.915 \\
\hline \multicolumn{4}{|l|}{$\begin{array}{l}\text { Qualidade do ajustamento } \\
\text { (probit) }\end{array}$} \\
\hline Predições corretas: & & & $90,82 \%$ \\
\hline Predições incorretas: & & & $9,18 \%$ \\
\hline Falsos positivos: & & & $0,38 \%$ \\
\hline Falsos negativos: & & & $8,80 \%$ \\
\hline Probabilidade média $(\mathrm{d}=1)$ : & & & 0,1049 \\
\hline
\end{tabular}

Fonte: Elaboração própria a partir dos dados da PNAD de 1996.

Nota: Erros-padrão robustos à heterocedasticidade entre parênteses. ***Estatisticamente significante a 1\%. * Estatisticamente significante a 5\%. *Estatisticamente significante a $10 \%$. Todas as regressões consideram peso amostral estimativas de erros-padrão conforme o plano amostral complexo. Matriz de covariância ajustada para inclusão das variáveis de seleção conforme Heckman (1976).

A quantidade de outras famílias conviventes no domicílio (variável instrumental - restrição de exclusão) registra uma relação não linear (côncava) com a probabilidade de o filho corresidir com o pai na vida adulta. Conforme já ressaltado, neste estudo esta variável é uma proxy para custos/benefícios (monetários e/ ou psicológicos) de moradia conjunta. Os sinais estimados para os coeficientes da 
parte linear e quadrática sugerem que a presença de outras famílias favorece o acolhimento o filho adulto enquanto dependente, mesmo que a taxas decrescentes. Por exemplo, considerando uma média de 0,20 da variável em destaque na amostra, é possível inferir que cada família a mais no domicílio aumenta a probabilidade de corresidência do filho com o pai em cerca de 6,8 p.p (vide Tabela 6, no Apêndice A). Ou seja, os resultados sugerem que filhos adultos são mais propensos a corresidir em com os pais em domicílios onde exista mais de uma família. Assim, parece haver uma predominância de benefícios (apoio financeiro/pessoal) frente aos custos de moradia.

Tais evidências são reforçadas a partir de testes estatísticos para restrição de exclusão no modelo empírico analisado. A Tabela 7, no Apêndice A, reporta os resultados do teste proposto por Huber e Mellace (2015) para restrições conjuntas, desigualdades que asseguram a identificação pontual e por intervalos para a variável de resposta (anos de estudo do filho adulto) mediante a premissa de independência de instrumentos - ver desigualdades representadas em (8). Cada linha na tabela em foco representa subamostras condicionadas a diferentes subconjuntos de valores para covariadas. A coluna (1) informa a estimativa da percentagem de indivíduos compliers em cada amostra (percentual de defiers se negativo). ${ }^{13}$ Nas colunas (2) e (3) se encontram as estimativas de distâncias máximas padronizadas, respectivamente, para os grupos de filhos corresidentes e não corresidentes. ${ }^{14}$ Conforme ressaltado por Huber e Mellace (2015), tais distâncias mensuram o grau de violação de restriçõesdo teste. Ou seja, valores elevados e positivos indicam rejeição da hipótese nula de validade do instrumento, enquanto valores negativos informam o oposto. Por último, as colunas (a), (b) e (c) apresentam as estatísticasp-valor conforme diferentes métodos para testes conjuntos de restrições de desigualdade, respectivamente, Chen e Szroeter (2014), Bennett (2009) - recentramento parcial e Bennett (2009) - recentramento completo. ${ }^{15}$

Os resultados apontam que, para a maioria das amostras condicionadas, os valores das distâncias máximas padronizadas são negativos e as estatísticas de p-valor, superiores a 0,01 ou 1\%. Destarte, em geral, não há indícios para rejeitar a

13 Conforme já destacado na metodologia, compliers representam indivíduos que teoricamente assumiriam a posição de tratamento (corresidência) no caso de aumento do valor do instrumento binário $Z_{\mathrm{i}}$. Já os defiers são aqueles com comportamento inverso, isto é, tornar-se-iam tratados mediante uma redução do valor do instrumento. Vale de destacar que Huber e Mellace (2015) demonstram que o teste proposto torna-se mais robusto à medida que diminui o percentual de compliers. Para viabilizar a aplicação do teste, seguiu-se o método dos referidos autores para dicotomizar a variável de instrumento atribuindo-se valor igual 1 para casos superiores à mediana e 0 caso contrário.

14 Ver conjunto de desigualdades do teste (8). Os coeficientes $\hat{\gamma}_{1}, \hat{\gamma}_{2}, \hat{\gamma}_{3}$ e $\hat{\gamma}_{4}$ são valores médios obtidos para as restrições em destaque (inclusive com pesos da amostra); $\sigma_{\mathrm{s}}$ é o desvio-padrão da variável anos de estudo do filho em cada subamostra (considerando plano amostral) e max a função de valor máximo.

15 Para mais detalhes, vide Bennett (2009), Chen e Szroeter (2014) e Huber e Mellace (2015). 
hipótese de validade da restrição de exclusão, especialmente nos casos de maior robustez, isto é, quando há um baixo percentual de compliers (valores positivos).

\section{Considerações Finais}

O presente estudo buscou estimar, de uma forma robusta, o grau de persistência (mobilidade) intergeracional de educação para o Brasil. Adicionalmente, buscou-se investigar se a não contabilização dos filhos corresidentes gera vieses na estimativa de indicadores de mobilidade. Para tanto, a partir de dados da PNAD de 1996 com plano amostral complexo e de um modelo empírico de determinação conjunta das decisões de corresidência e acumulação de capital humano foi realizada uma revisão dos resultados do estudo de Ferreira e Veloso (2003), que é considerado como uma importante referência no campo de pesquisa.

Os resultados empíricos indicaram que os coeficientes de persistência educacional, tradicionalmente estimados para o Brasil, não podem ser generalizados para a toda a população, ou seja, além de diferentes para os grupos de filhos dependentes (corresidentes) e filhos independentes (chefes/cônjuges), suas estimativas tornam-se tendenciosas quando não considerada a inter-relação entre as decisões de acumulação de capital humano e de convivência dos filhos com os pais na vida adulta. Ademais, foram encontradas evidências de menor (maior) persistência (mobilidade) intergeracional para o grupo de filhos corresidentes.

Em paralelo, os achados sugerem uma relação entre escolaridade dos pais e corresidência dos filhos adultos. Contudo, caso a residência esteja localizada em áreas urbanas, a probabilidade de corresidir com os pais diminui. Há também uma assimetria dos resultados quando se consideram os efeitos das regiões geográficas tanto no que se refere às medidas de persistência intergeracional educacional, quanto no tocante às decisões de corresidência.

No geral, as evidências deste trabalho servem como parâmetros mais sólidos para estudos futuros com bases de dados mais recentes. Neste sentido, é fundamental que se leve em conta as transformações profundas ocorridas na dinâmica econômica dos últimos anos, sobretudo os avanços de natureza tecnológica que tiveram larga disseminação.

\section{Referências}

ATKINSON, A. On intergenerational income mobility in Britain. Journal of Post Keynesian Economics, v. 3, n. 2, p. 194-218, 1981.

BARROS, R. et al. Determinantes do desempenho educacional no Brasil. Pesquisa e Planejamento Econômico, v. 31, n. 1, p. 1-42, 2001. 
BARROS, R.; LAM, D. Desigualdade de renda, desigualdade em educação e escolaridade das crianças no Brasil. Pesquisa e Planejamento Econômico, v. 23, n. 2, p. 191-218, 1993.

BECKER, G. S. A treatise on the family. Cambridge: Harvard University Press, 1993.

BECKER, G. S.; MURPHY, K. M.; TAMURA, R. Human capital, fertility, and economic growth. Journal of Political Economy, v. 98, n. 5, p. 12-37, 1990.

BEHRMAN, J. R. et al. Intergenerational mobility in Latin America. Economía - Journal of the Latin American and Caribbean Economic Association, v. 2, n. 1, p. 1-44, 2001.

BENNETT, C. J. Consistent and asymptotically unbiased MinP tests of multiple inequality moment restrictions. Nashville: Vanderbilt University Department of Economics, 2009. (Working Paper, n. 09-W08). Disponível em: < https://ideas.repec.org/p/van/wpaper/0908. html>. Acesso em: 10 out. 2014.

BICKENBACH, F.; BODE, E. Markov or not Markov: this should be a question. Kiel: Kiel Institute for the World Economy, 2001. (Kiel Working Paper, n. 1086).

BORJAS, G. J. Ethnic capital and intergenerational mobility. The Quarterly Journal of Economics, v. 107, n. 1, p. 123-150, 1992.

CHEN, L.-Y.; SZROETER, J. Testing multiple inequality hypotheses: a smoothed indicator approach. Journal of Econometrics, v. 178, p. 678-693, 2014.

COBB-CLARK, D. A.; GORGENS, T. Parents' economic support of young-adult children: Do socioeconomic circumstances matter? Journal of Population Economics, v. 27, n. 2, p. 447471, 2014.

COUCH, K. A.; DUNN, T. A. Intergenerational correlations in labor market status: a comparison of the United States and Germany. The Journal of Human Resources, v. 32, n. 1, p. 210-232, 1997.

ERMISCH, J.; FRANCESCONI, M. Family matters: Impacts of family background on educational attainments. Economica, v. 68, n. 270, p. 137-156, 2001.

FERREIRA, S. G.; VELOSO, F. A. Intergenerational mobility of wages in Brazil. Brazilian Review of Econometrics, v. 26, n. 2, p. 181-211, 2006.

Mobilidade intergeracional de educação no Brasil. Pesquisa e Planejamento Econômico, v. 33, n. 3, p. 481-513, 2003.

FIELDS, G. S.; OK, E. A. The meaning and measurement of income mobility. Journal of Economic Theory, v. 71, n. 2, p. 349-377, 1996.

FIGUEIRÊDO, E. A.; NETTO JÚNIOR, J. L.; PÔRTO JÚNIOR, S. S. Distribuição, mobilidade e polarização de renda no Brasil: 1987 a 2003. Revista Brasileira de Economia, v. 61, n. 1, p. 7-32, 2007.

GALOR, O.; TSIDDON, D. Technological progress, mobility, and economic growth. The American Economic Review, v. 87, n. 3, p. 363-382, 1997. 
GALOR, O.; ZEIRA, J. Income distribution and macroeconomics. Review of Economic Studies, v. 60, n. 1, p. 35-52, 1993.

GIANNELLI, G. C.; MONFARDINI, C. Joint decisions on household membership and human capital accumulation of youths. The role of expected earnings and local markets. Journal of Population Economics, v. 16, n. 2, p. 265-285, 2003.

HECKMAN, J. Sample selection bias as specification error. Econometrica, v. 47, n. 1, p. 153$162,1979$.

. The common structure of statistical models of truncation, sample selection and limited dependent variables and a simple estimator for such models. Annals of Economic and Social Measurement, v. 5, n. 4, p. 475-492, 1976.

. Varieties of selection bias. American Economic Review, v. 80, n. 2, p. 313-318, 1990. HECKMAN, J.; NAVARRO-LOZANO, S. Using marching, instrumental variables, and control functions to estimate economic choice models. The Review of Economics and Statistics, v. 86, n. 1, p. 30-57, 2004.

HUBER, M.; MELLACE, G. Testing instrument validity for LATE identification based on inequality moment constraints. Review of Economics and Statistics, v. 97, n. 2, p. 398-411, 2015 .

IBGE. Pesquisa Nacional por Amostra de Domicílios (PNAD) 1996. Disponível em: < http:// www.ibge.gov.br>. Acesso em: 05 jun. 2014.

LEE, L. Unionism and wage rates: a simultaneous equations model with qualitative and limited dependent variables. International Economic Review, v. 19, n. 2, p. 415-433, 1978.

LUCAS, R. J. On the mechanics of economic development. Journal of Monetary Economics, v. 22, n. 1, p. 3-42, 1988.

MACHADO, D. C.; GONZAGA, G. O impacto dos fatores familiares sobre a defasagem idade-série de crianças no Brasil. Revista Brasileira de Economia, v. 61, n. 12, p. 449-476, 2007.

MULLIGAN, C. Parental priorities and economic inequality. Chicago: University of Chicago Press, 1997.

NETTO JÚNIOR, J. L.; PÔRTO JÚNIOR, S. S.; FIGUEIRÊDO, E. A. Migração e Distribuição de capital humano no Brasil: mobilidade intergeracional educacional e intrageracional de renda. Revista Brasileira de Economia, v. 39, n. 4, p. 404-427, 2007.

NICOLETTI, C.; ERMISCH, J. Intergenerational earnings mobility: changes across cohorts in Britain. The B.E. Journal of Economic Analysis \& Policy, v. 7, n. 2, p. 1-38, 2008.

PERO, V.; SZERMAN, D. Mobilidade intergeracional de renda no Brasil. Pesquisa e Planejamento Econômico, v. 38, n. 1, p. 1-36, 2008.

PESSOA, D. G. C.; COSTA, A. W. N. D. Introdução à análise de dados amostrais complexos. 2013. Disponível em : <https://djalmapessoa.github.io/adac>. Acesso em: 01 set. 2014. 
SÁ, C. et al. Higher education (related) choices in Portugal: joint decisions on institution type and leaving home. Studies in Higher Education, v. 36, n. 6, p. 689-703, 2011.

SILVA, P. L. N.; PESSOA, D. G. C.; LILA, M. F. Análise estatística de dados da PNAD: incorporando a estrutura do plano amostral. Ciência Ė Saúde Coletiva, v. 7, n. 4, p. 659-670, 2002.

SIMON, C.; BLUME, L. Mathematics for Economists. New York: Norton, 1994.

SISON, C. P.; GLAZ, J. Simultaneous confidence intervals for multinomial proportions. Journal of the American Statistical Association, v. 90, n. 429, p. 366-369, 1995.

TOOMET, O.; HENNINGSEN, A. Sample selection models in r: package sample selection. Journal of Statistical Software, v. 27, n. 7, p. 1-23, 2008.

\section{Apêndice A - Dados}

Tabela 4 - Estatísticas descritivas da amostra

\begin{tabular}{|c|c|}
\hline Variável & Definição \\
\hline Código do domicílio & $\begin{array}{l}\text { Identificador do domicílio. Variável formada pela concatenação } \\
\text { das seguintes variáveis: (UF) - unidade da federação, (V0102) - Nú- } \\
\text { mero do Controle e (V0103) - Número de Série }\end{array}$ \\
\hline Estrato & (V4617) Identificador do estrato da amostra \\
\hline $\begin{array}{l}\text { Unidade primária da } \\
\text { amostra (PSU) }\end{array}$ & (V4618) Identificador da unidade primária da amostra. \\
\hline Peso amostral & (V4729) Peso amostral de cada pessoa entrevistada. \\
\hline $\begin{array}{l}\text { Anos de estudo } \\
\text { (filho) }\end{array}$ & (V4703) - Anos completos de estudo \\
\hline Anos de estudo (pai) & $\begin{array}{l}\text { (V4703; V1217) Nível de instrução do pai. No caso dos filhos eman- } \\
\text { cipados, recebeu o valor 0, caso o pai tenha menos de } 1 \text { ano de } \\
\text { estudo; } 2 \text { caso tenha completado a primeira, segunda ou terceira } \\
\text { série do ensino fundamental ou quarta série incompleta; } 4 \text { se com- } \\
\text { pletou a quarta série; } 6 \text { se concluiu a quinta, sexta ou sétima série, } \\
\text { mesmo sem completar a oitava série; } 8 \text { se concluiu a oitava série; } \\
10 \text { caso possua ensino médio não concluído; } 11 \text { se completou o } \\
\text { ensino médio; } 13 \text { se cursou algum curso superior e não concluiu o } \\
\text { mesmo ou tem } 15 \text { anos de escolaridade sem completar curso supe- } \\
\text { rior; } 16 \text { caso tenha curso superior completo ou frequentado pós- } \\
\text {-graduação. Já no caso dos filhos corresidentes, a compatibilização } \\
\text { procedeu da seguinte forma: o nível de instrução do pai recebeu } \\
\text { o valor } 0 \text {, caso o pai tenha registrado menos de } 1 \text { ano de estudo; } \\
2 \text { caso tenha de } 1 \text { a } 3 \text { anos completos de estudo; } 4 \text { se completou } 4 \\
\text { anos de estudo; } 6 \text { se possui de } 5 \text { a } 7 \text { anos de estudo; } 8 \text { se registra } 8 \\
\text { anos de estudo; } 10 \text { se tem de } 9 \text { a } 10 \text { anos de estudo; } 11 \text { caso tenha } \\
11 \text { anos de estudo; } 13 \text { se registra de } 12 \text { a } 15 \text { anos de estudo e sem } \\
\text { completar curso superior; } 16 \text { se tem } 15 \text { ou mais anos de estudo } \\
\text { tendo completado o curso superior ou frequentado pós-graduação. }\end{array}$ \\
\hline
\end{tabular}


conclusão.

\begin{tabular}{l|l}
\hline \multicolumn{1}{c|}{ Variável } & \multicolumn{1}{c}{ Definição } \\
\hline Cor preta & (V0404) 1 - se o filho declarou-se de cor preta e 0 - caso contrário*. \\
\hline Idade & (V8005) Idade do filho em anos. \\
\hline Idade ao quadrado & $\begin{array}{l}\text { (V8005) Idade do filho em anos elevada ao quadrado (experiên- } \\
\text { cia). }\end{array}$ \\
\hline Zona urbana & (V4728) 1 - se o filho reside em zona urbana e 0 - em zona rural*. \\
\hline Norte & $\begin{array}{l}\text { (UF) 1 - se o filho reside na região Norte e 0 - se reside na região } \\
\text { Sudeste* }\end{array}$ \\
\hline Nordeste & $\begin{array}{l}\text { (UF) 1 - se o filho reside na região Nordeste e 0 - se reside na re- } \\
\text { gião Sudeste* }\end{array}$ \\
\hline Centro-Oeste & $\begin{array}{l}\text { (UF) 1 - se o filho reside na região Sul e 0 - se reside na região } \\
\text { Sudeste* }\end{array}$ \\
\hline $\begin{array}{l}\text { Outras famílias no } \\
\text { domicílio }\end{array}$ & $\begin{array}{l}\text { (UF) 1 - se o filho reside na região Centro - Oeste e 0 - se reside na } \\
\text { região Sudeste* }\end{array}$ \\
\hline $\begin{array}{l}\text { (V0403) - Total de outras famílias convivendo no mesmo domicílio. } \\
\text { Após dicotomizar esta variável atribuindo 1 se o número da família } \\
\text { é superior a 1 e 0 caso contrário, foi realizada a soma por código } \\
\text { do domicílio. }\end{array}$ \\
\hline $\begin{array}{l}\text { Outras famílias no } \\
\text { domicílio ao qua- } \\
\text { drado }\end{array}$ & $\begin{array}{l}\text { (V0403) - Total de outras famílias convivendo no mesmo domicílio. } \\
\text { Após dicotomizar esta variável atribuindo 1 se o número da família } \\
\text { é superior a 1 e 0 caso contrário, foi realizada a soma por código } \\
\text { do domicílio. Finalmente esta variável foi elevada à segunda po- } \\
\text { tência }\end{array}$ \\
\hline Fonte: Elabara
\end{tabular}

Fonte: Elaboração própria a partir dos dados da PNAD de 1996.

Nota: * Categoria omitida. Variável de origem do dicionário da PNAD entre parênteses. 
Tabela 5 - Regressões com diferentes especificações - coeficiente de persistência intergeracional segundo condição de corresidência

\begin{tabular}{l|c|c|c|c|c}
\hline \multicolumn{1}{c|}{ Modelo/variável } & (1) & (2) & (3) & (4) & (5) \\
\hline $\begin{array}{l}\text { Amostra I: Filhos não } \\
\text { corresidentes }\end{array}$ & & & & & \\
Anos de estudo (pai) & $0,8043^{* * *}$ & $0,7831^{* * *}$ & $0,7776^{* * *}$ & $0,7134 * * *$ & $0,6976^{* * *}$ \\
& $(0,0065)$ & $(0,0066)$ & $(0,0067)$ & $(0,0066)$ & $(0,0066)$ \\
$\mathrm{R}^{2}$ ajustado & 0,3291 & 0,3502 & 0,3526 & 0,4005 & 0,4114 \\
Amostra II: Filhos corre- & & & & & \\
sidentes & & & & & \\
Anos de estudo (pai) & $0,6642 * * *$ & $0,6563 * * *$ & $0,6528 * * *$ & $0,5781^{* * *}$ & $0,5530^{* * *}$ \\
& $(0,0146)$ & $(0,0148)$ & $(0,0148)$ & $(0,0151)$ & $(0,0152)$ \\
$\mathrm{R}^{2}$ ajustado & 0,2976 & 0,3029 & 0,3050 & 0,3538 & 0,3750 \\
Especificações & & & & & Sim \\
Idade & Não & Sim & Sim & Sim & Sim \\
Idade ao quadrado & Não & Sim & Sim & Sim & Sim \\
Cor preta & Não & Não & Sim & Sim & Sim \\
Zona urbana & Não & Não & Não & Sim & Sim \\
Dummies regionais & Não & Não & Não & Não & Sim \\
\hline
\end{tabular}

Nota: Erros-padrão robustos à heterocedasticidade entre parênteses. ***Estatisticamente significante a 1\%. **Estatisticamente significante a 5\%. *Estatisticamente significante a 10\%. Todas as regressões consideram peso amostral e estimativas de erros-padrão conforme o plano amostral complexo. 
Tabela 6 - Regressão Probit - Efeitos marginais na média das covariadas

\begin{tabular}{lccc}
\hline \multicolumn{1}{c}{ Variável } & Efeito Marginal & Erro-Padrão & Estatística Z \\
\hline Anos de estudo (pai) & $0,0037 * * *$ & 0,0004 & 10,6389 \\
Cor preta & $-0,0025$ & 0,0056 & $-0,4482$ \\
Idade & $-0,0241 * * *$ & 0,0013 & $-18,0408$ \\
Idade ao quadrado & $0,0002 * * *$ & 0,0000 & 9,2523 \\
Zona urbana & $-0,0312 * * *$ & 0,0032 & $-9,6585$ \\
Norte & $-0,0202 * * *$ & 0,0057 & $-3,5345$ \\
Nordeste & $-0,0087 * * *$ & 0,0032 & $-2,6985$ \\
Sul & $-0,0214 * * *$ & 0,0037 & $-5,7104$ \\
Centro-Oeste & $-0,0430 * * *$ & 0,0045 & $-9,6149$ \\
Outras famílias no domicílio & $0,0699 * * *$ & 0,0025 & 27,5847 \\
Outras famílias (ao quadrado) & $-0,0040 * * *$ & 0,0004 & $-9,2842$ \\
\hline
\end{tabular}

Fonte: Elaboração própria a partir dos dados da PNAD de 1996.

Nota: Erros-padrão e estatística Z obtidos por 1.999 reamostragens com reposição (bootstrap), considerando pesos amostrais nas reestimativas dos coeficientes do modelo de regressão probit. *** Estatisticamente significante a 1\%. 


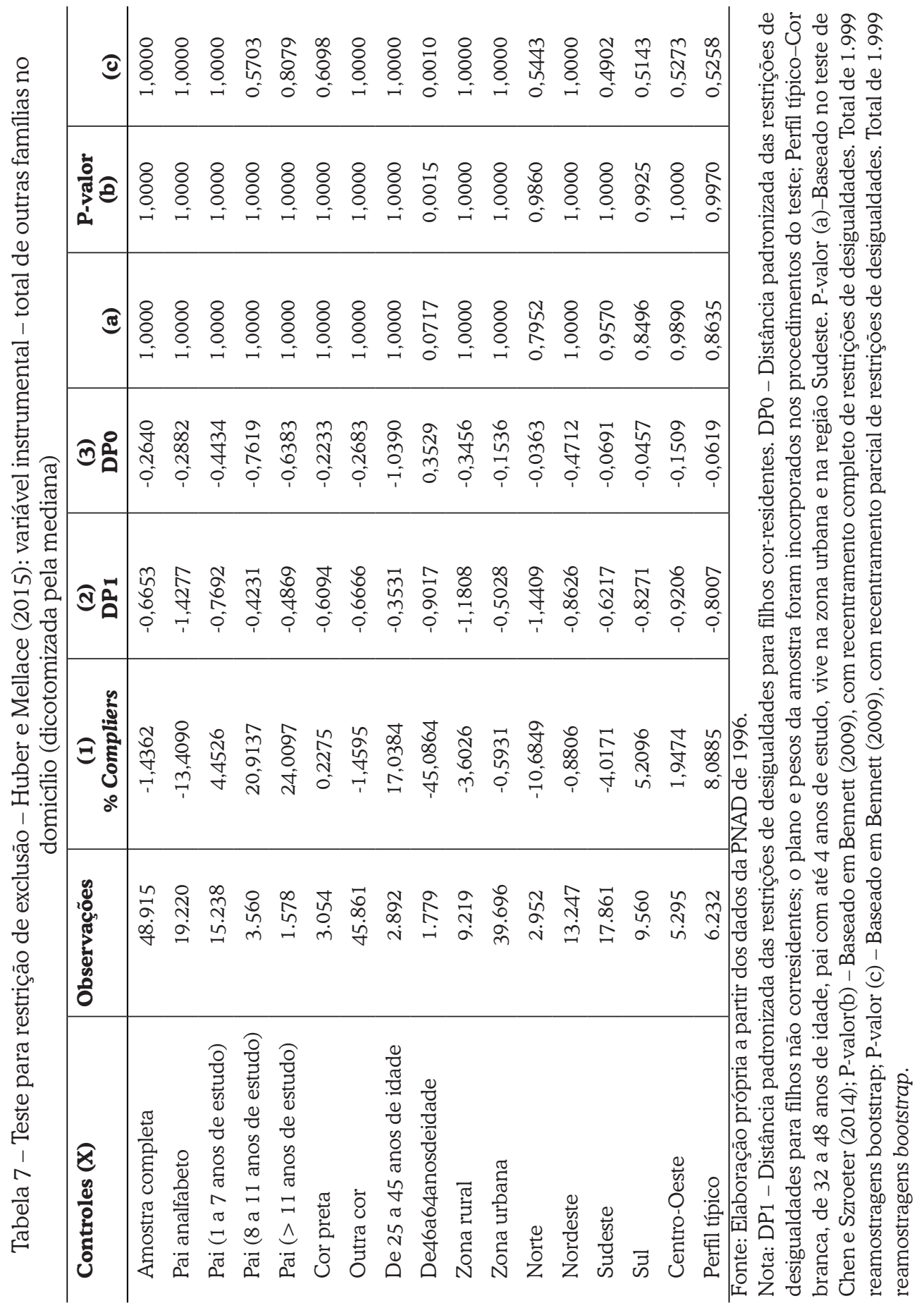


Recebido em: 19/01/2015.

Aceito em: 24/02/2017. 